\title{
Overview of automotive engine friction and reduction trends- Effects of surface, material, and lubricant-additive technologies
}

\author{
Victor W. WONG ${ }^{1, *}$, Simon C. TUNG ${ }^{2, *}$ \\ ${ }^{1}$ Massachusetts Institute of Technology, Cambridge, MA 02139, USA \\ ${ }^{2}$ Vanderbilt Chemicals LLC, Norwalk, CT 06856, USA \\ Received: 06 January 2016 / Revised: 26 February2016 / Accepted: 29 February 2016 \\ (C) The author(s) 2016. This article is published with open access at Springerlink.com
}

\begin{abstract}
The increasing global environmental awareness, evidenced by recent worldwide calls for control of climate change and greenhouse emissions, has placed significant new technical mandates for automotives to improve engine efficiency, which is directly related to the production of carbon dioxide, a major greenhouse gas. Reduction of parasitic losses of the vehicle, powertrain and the engine systems is a key component of energy conservation. For engine efficiency improvement, various approaches include improvements in advanced combustion systems, component system design and handling - such as down-sizing, boosting, and electrification-as well as waste heat recovery systems etc. Among these approaches, engine friction reduction is a key and relatively cost-effective approach, which has been receiving significant attention from tribologists and lubricant-lubrication engineers alike. In this paper, the fundamentals of friction specific to the environments of engine components tribology are reviewed, together with discussions on the impact of developing vehicle powertrain technologies, surface and material technologies, as well as lubricant and additive technologies on promises of continuing friction and wear reduction trends. The international accords on climate change require further gains in fuel efficiency and energy sustainability from all industry sectors including those in the automotive and the broader internal combustion engine industries, and the latter encompass off-highway, power generation, marine, and rail industries as well. This paper focsuses on friction reduction in mainly automotive engines, however.
\end{abstract}

The paper starts with a clarification of the common descriptors of mechanical losses and friction in the engine, followed by the topic of lubrication fundamentals such as lubrication regimes. Then the lubrication of the contacting surfaces in each of the major engine subsystems is discussed in turn. These subsystems include the piston assembly: ring-pack/liner, piston-skirt/liner, and piston-pin/connecting-rod contacts; connecting rod and crankshaft bearings; and the valvetrain subsystem. The relative contributions to total friction from the various subsystems are discussed, with the piston-assembly contributing to about half of the total friction. The remainder of the friction comes from the crankshaft, connecting rod, camshaft bearings, and the valvetrain oscillating parts. The bearings are in predominantly hydrodynamic lubrication, in contrast to the valvetrain oscillating components, which are characterized to be mostly in the mixed/boundary lubrication regimes.

Despite the title of the paper, a section on emerging powertrain technologies-including that of combustion in gasoline and diesel engines-is also given in the context of the trend towards clean and efficient propulsion systems. The impact of these developing technologies on the reduction of friction and parasitic losses via component, material, and lubricant deisgn will be discussed. These technologies include gasoline direct injection (GDI), turbocharged, and hybrid vehicles and will generate unique green environmental opportunities for future propulsion systems. These technologies are critical to meet fuel economy and reduced emission targets. Specifically, this paper will address the impact of these emerging technologies on future lubricant requirements and advanced tribology research. The connection between these lubricant and tribological requirements will be

* Corresponding author: Victor W. WONG. E-mail: vwong@mit.edu; Simon C. TUNG. E-mail: STung@vanderbiltchemicals.com 
illustrated by briefly describing the basic lubrication and friction processes at the major engine components incorporating the emerging technologies.

Lastly, besides new hardware and material science changes, several advanced additives such as advanced friction modifiers, antiwear additive chemistries, low viscosity lubricants, and the introduction of new VI Improvers all represent possible tribological solutions to the challenge of meeting more stringent energy efficiency requirements and environmental legislation. As original equipment manufacturers (OEMs) seek to accomplish these goals, hardware and emission system changes will place new demands and even greater stress on engine oils. At the same time, engine durability, performance and reliability are of primary importance to vehicle owners and operators. The final section of this paper will discuss the future trends of engine friction reduction and wear control by surface modification such as friction-reducing coatings or surface textures in engine components. The impact of surface coatings or surface textures on engine friction will be reviewed. In addition, the OEMs and lubricant formulation manufacturers will need to respond with novel engine oil technologies formulated to protect the engine, keeping the emissions system working at the optimal fuel economy, while retaining engine durability.

In brief, the paper (i) reviews the characteristics of component friction in the environment of the internal combustion engine and the relevant design considerations, (ii) addresses the impact of emerging technologies on engine friction and the tribological changes and requirements, especially on lubricant and additives, and lastly (iii) discusses the interactions between lubricant-additive formulations and material surface engineering, and their effects on friction, wear and engine durability. The increasing importance and interplay between synergistic advancements in component design, material and surface engineering, and advanced lubricant-additive formulation will be fully illustrated.

Keywords: powertrain tribology; automotive lubricants; additive formulation; mechanical design; surface coatings and textures; friction; wear

\section{Introduction}

The trend towards greater energy conservation and the reduction of green-house gases demands that fuel consumption of automotive engines continues to be improved. Although the useful work loss due to engine friction is relatively small for modern engines, the reduction of all parasitic energy losses, including friction, remains as a valuable contribution to overall efficiency improvement. A small gain in fuel consumption, even by $1 \%$ over existing levels, is an important achievement. The macroscopic energy and economic savings from improved engine efficiency are huge. Lubrication and friction play essential roles in energy conservation.

There are many moving parts in an engine. Proper lubrication keeps them in good working order, extends component longevity, and minimizes energy losses due to friction. Many engine durability and reliability issues, such as excessive wear, component seizure and catastrophic failure, are traced to problems with inadequate lubrication of essential components. Proper lubrication and low friction are associated with engine integrity and good performance, which are attributes important to the end user.

In recent years the automotive industry has undergone a revolution in hardware and materials. Driving these changes are global requirements for reduced emissions and improvements in vehicle fuel economy. Key advances in recent years include (1) introduction of the first gasoline direct injection Mitsubishi 4G9 engine in 1996, (2) introduction of the Toyota Prius to the Japanese market in 1997, and (3) use of the Holset VGT ${ }^{\mathrm{TM}}$ Variable Geometry (VG) turbocharger in commercial vehicles in 1998. These advances coincided with full phase-in of the United States Environmental Protection Agency Tier One policy between 1994 and 1997. The speed and magnitude of these advances has resulted in a change in the way lubricants are used in engines. As a result, significant technological changes are now taking place in the ways engine oils are formulated and the types of additives that are used.

Improvement of fuel economy has been one of 
the most important challenges for the automotive industry. However, in recent years, the industry has made large strides in improving energy consumption by lowering friction in passenger cars, trucks and buses [1, 2]. The turbocharged, direct-injection spark ignition engine with downsizing is one of the technical solutions that have been used in the market. In the case of diesel engines, the turbocharger has to be utilized to meet strict emissions regulations along with fuel economy improvement requirements. In both cases, engine oil technology plays a very important role in order to avoid potential problems in the market. This paper will address the impact of these technologies on future lubricant and tribology requirements.

The lubricant itself is a multi-constituent fluid that strongly influences the lubrication regime of the lubricated parts. Various additives provide different functions in the oil: to maintain the temperature sensitivity of the oil viscosity, to protect against wear through formation of surface films, and to reduce solid-to-solid friction by making the surfaces more slippery. In addition, other additives keep the component surfaces clean and maintain the oil properties to within acceptable levels. In recent years, lubricant additive derived ash in the exhaust stream has become an important issue in advanced diesel engines equipped with emission after treatment control systems. Engine design and the lubricant-additive formulation need to be optimized to simultaneously protect both the engine and the emission-control system from contamination by ash, sulfur and phosphorous originating in the oil.

\section{Engine component design and its impact on fuel economy and wear control}

Lubrication involves the smoothing of the rubbing process between contacting surfaces. A lubricant film between the surfaces would prevent direct solidto-solid contact. The degree of solid-to-solid contact and the oil film thickness depend on the applied mechanical load, relative velocity, surface profiles, roughness, textures, as well as lubricant properties. There are different types of lubrication conditions or regimes, the fundamentals of which will be illustrated. There are many contacting surfaces in an engine system: in the piston assembly, valve-train components, and multiple bearing surfaces. The relative magnitudes of friction in these components will be examined.

\subsection{Friction analyses and energy distribution}

While friction is a strong function of engine speed (rev/min), it varies less directly with engine load [3]. Increasing the power output for a given sized engine at a given speed (viz. increasing the bmep) is a typical strategy of reducing friction as a percentage of engine work output. There are typical estimates of the relative magnitude of friction for common engine size and power output classes; however, these mostly empirically based estimates [4-6] span a wide range and do not point to a simple distribution quantitatively.

A typical estimate of friction for a fired engine (diesel or SI), however, as a fraction of total fuel energy used is shown in Fig. 1 [7], in which mechanical friction is shown to take up roughly $4 \%-15 \%$ of the total fuel energy. This general estimate reflects typical in-use engine conditions, on the aggregate over various operating conditions, and does not apply to unique extreme conditions such as at idling and at very light loads where most of the fuel energy is consumed to overcome friction, with no net power output. Thermal efficiencies (work output/fuel used) of modern engines vary between $38 \%-50 \%$, with $50 \%$ being a common development goal. Accordingly, mechanical friction is typically $10 \%-30 \%$ of engine power output, although it could be $100 \%$, at idling, at the extreme.

The above estimate of mechanical friction is consistent with other estimates of total mechanical losses in an engine, which include pumping and accessory losses in addition to mechanical friction itself, at up to $40 \%$ of the gross (indicated) power output from the engine [8-11]. Most of the mechanical losses, about $75 \%$, are rubbing friction, although the relative

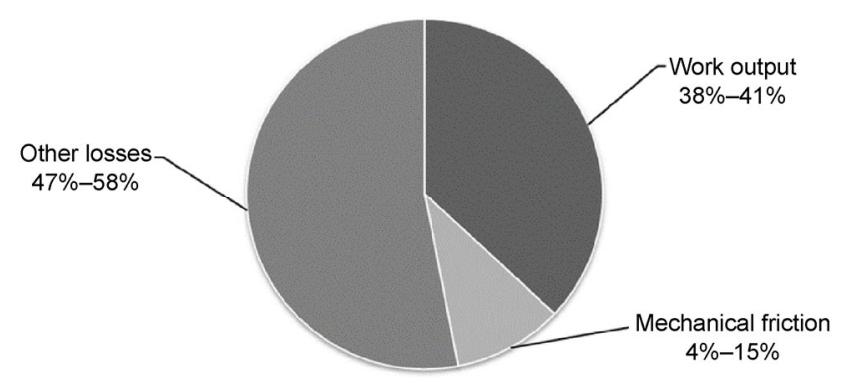

Fig. 1 Distribution of total energy in a fired engine [7]. 
pumping losses become more significant at lighter loads [12].

As engine power output from a given engine increases, friction becomes less as a percentage of power output. Therefore, mechanical efficiency typically increases with engine load. Friction could be a small fraction of engine power output, at $10 \%$ or less at high loads, and its relative importance increases at lighter loads, at $30 \%$ or more at part loads.

\subsection{Breakdown of friction by engine components}

Exclusions: Pumping losses result from the flow of intake and exhaust gases. Accessories include coolant and lubricant pump, fans, and other pneumatic systems that may be powered directly by the engine. The losses in these systems depend on parameters other than the traditional concept of lubrication or a lubricant. They comprise $20 \%-30 \%$ of total mechanical losses for accessories for heavy-duty diesels and 30\%-50\% for pumping loss for gasoline engines, depending on the operating speed and load. While important, these losses are not included in the current focused discussions on mechanical or rubbing friction. With the above exclusions, the three major subsystems of the engine contributing to mechanical friction are thus: (a) piston-ring-liner system, (b) crankshaft and bearings system, and (c) valvetrain system. The exact distribution of the friction among these three groups depends on the particular engine, the component design details, and operating conditions. However, prevalent reported results show that the crankshaft system (main bearing and seals) contributes roughly $50 \%-100 \%$ higher friction than the valvetrain system, and the power cylinder friction approximately equals

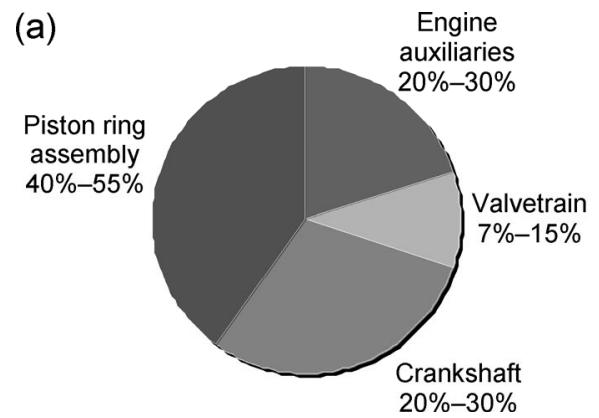

that from the valvetrain and bearing systems combined. Figure 2 shows a typical partitioning of the mechanical friction in the engine, among the three major component groups [7, 11, 13]. Friction and lubrication in these components groups will next be discussed.

\subsection{The piston-assembly system}

The piston assembly consists of the piston, piston rings, piston pin, connecting rod and bearings, as shown schematically in Fig. 3. There are three main friction and lubrication groups: (a) the piston-skirt surfaces sliding up and down the liner, (b) the ring-face surfaces of the ring pack likewise in reciprocating motion along the liner, and (c) the bearing surfaces in rotating motion in the wrist pin and connecting rods. The friction and lubrication in the bearings are similar to that in the crankshaft main bearings and thus will be discussed in the next section. Most of the pistonassembly friction comes from either (i) piston-skirt/ liner interaction, or (ii) ring-pack/liner interaction. Strictly speaking, there is also lubrication and friction as the rings slide radially against the inside surfaces of the ring grooves in which the rings reside. However, the ring-groove interactions are only intermittent and do not contribute significantly to energy losses, but rather to ring-grooves wear issues.

\subsubsection{The piston-skirt-liner subsystem}

Because of the kinematics of the connecting rod transmitting the piston reciprocating motion to rotating crank motion, side forces act on the piston laterally, causing what is termed secondary motion of the piston inside the cylinder. Piston secondary motion results primarily in (a) a variable slight tilt of the

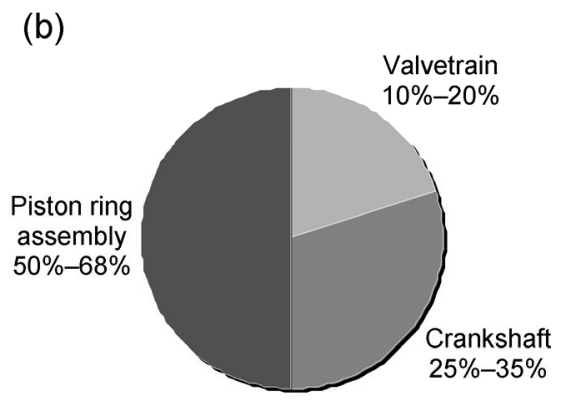

Fig. 2 Distribution of total mechanical losses and friction on in a diesel engine [7, 11, 13]: (a) distribution of total mechanical losses, and (b) distribution of friction. 


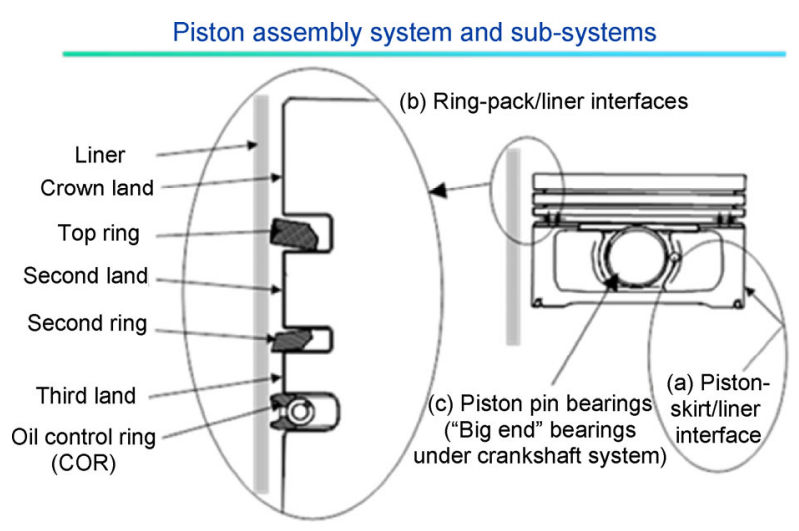

Fig. 3 Piston assembly system showing (a) piston-skirt/liner subsystem, (b) ring-pack/liner subsystem, and (c) piston-pin/piston bearing surfaces. Con-rod "big end" bearings under Crankshaft section.

piston as it rotates about the piston-pin, and (b) an impact force, commonly called piston slap, of the piston as it switches from sliding up on one side of the liner (minor-thrust or anti-thrust side) to sliding down on the other side (major-thrust or, or thrust side) of the liner. The piston tilt is affected to a large extent by the skirt profile, while the operating clearance between the piston and liner, and the thickness of the oil film thickness between them, significantly affect the side impact force. Although the piston rings provide vital sealing functions, the side forces on the piston are supported mainly by the piston skirts instead. The rings move relatively freely in their grooves and do not exert much side force on the piston other than through the friction on the ring groove surfaces.

The lubrication regimes and friction losses in the piston-skirt-liner subsystem are significantly influenced by the piston secondary motion. As one would expect, skirt-liner friction is higher when there is solid-solid contact in the boundary lubrication and mixed lubrication regimes. The axially barrel-shaped skirt profile is expected to provide the hydrodynamic pressure to sufficiently separate the skirt from the liner in maintaining hydrodynamic lubrication. However, when the piston speed approaches zero at the ends of the piston travel up or down strokes, the squeeze-film damping there remains as the essential mechanism to maintain a reasonably oil film, often not thick enough to avoid solid-solid contact.

The important parameters governing piston skirtliner friction include the surface characteristics, such as textures or waviness patterns on the skirt and surface roughness; skirt design details such as ovality and axial profile, and lubricant thickness and rheology.

The piston skirt is considered compliant and flexible in response to mechanical loads such as the oil film pressure itself. The mechanical deformations add challenge in predicting skirt-liner lubrication. It was reported [14] that a more compliant skirt provides a greater separation between the skirt and liner surface, thus lower friction, as shown in Fig. 4, where computationally the flexibility (deformation response to applied load) of the skirt was reduced to zero (rigid skirt) or made several times more compliant.

Figure 5 [15] illustrates conceptually typical effects of increasing viscosity in piston-skirt friction, where the hydrodynamic friction increases and boundary friction decreases with increasing oil viscosity for a skirt design with a fair amount of boundary lubrication. In this case, a thicker oil maintains a larger skirt-liner separation and consistently reduces friction. In Fig. 5 also, however, in a different skirt design with less boundary lubrication, increasing oil viscosity would increase friction beyond an optimal point, as hydrodynamic lubrication becomes dominant and a lower viscosity would decrease friction.

The key in reducing piston skirt-liner friction lies in maintaining hydrodynamic lubrication of the skirt. With an adequate oil supply to the skirt, most other issues of skirt profile design and surface characteristics affecting boundary lubrication would disappear or

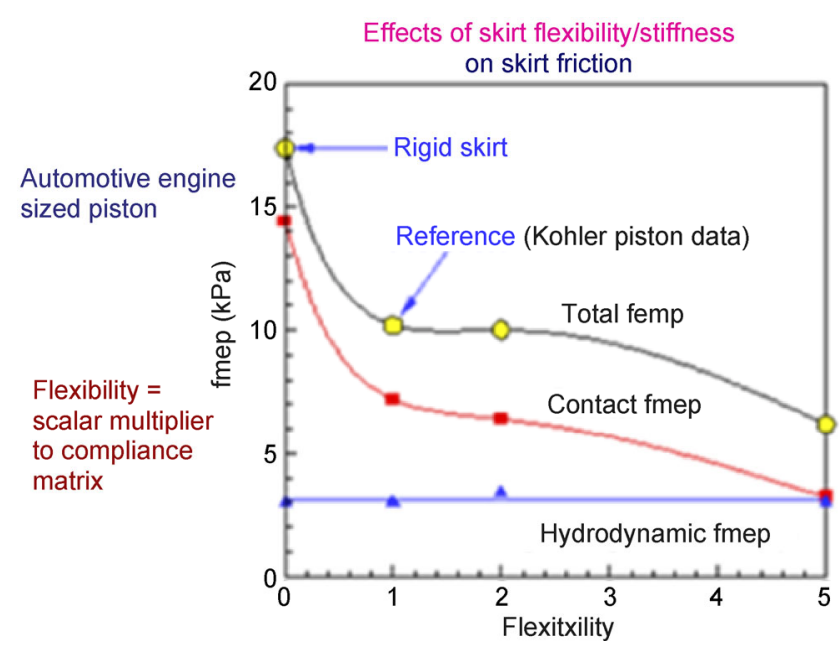

Fig. 4 Effects of piston-skirt flexibility/stiffness on skirt-liner friction [14]. 


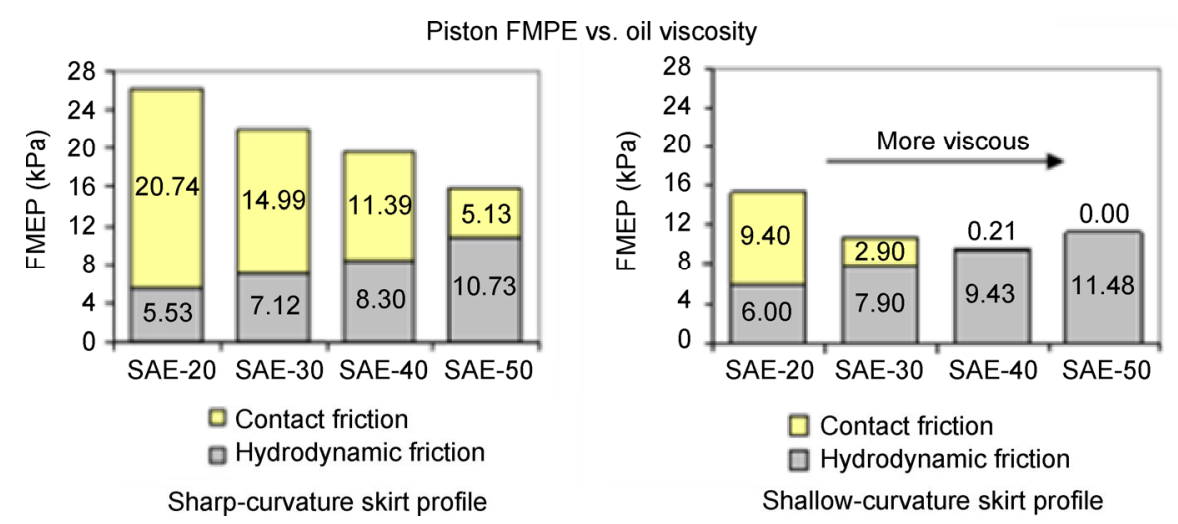

Fig. 5 Computer calculations [15] showing effects of oil viscosity on piston-skirt/liner friction, illustrating dependence on degree of mixed/boundary lubrication: (left) significant mixed-boundary lubrication; (right) moderate mixed-boundary lubrication.

diminish. This is illustrated in Fig. 6, where it is shown [14] that piston-skirt friction can be reduced by reducing primarily the boundary contacts between the liner and skirt surfaces; this can be achieved by providing ample oil supply to the skirt.

\subsubsection{The piston ring-pack subsystem}

An automotive-engine piston ring pack usually consists of three rings as shown in Fig. 3. Uninstalled, the top two rings have diameters larger than the cylinder bore. When compressed and installed in the grooves in the piston and fit into the cylinder liner, they expand against the liner, and this force is called the ring tension. The third ring from the top is the oil-control ring, which is either of a two-piece design in many diesel engines or a three-piece design in

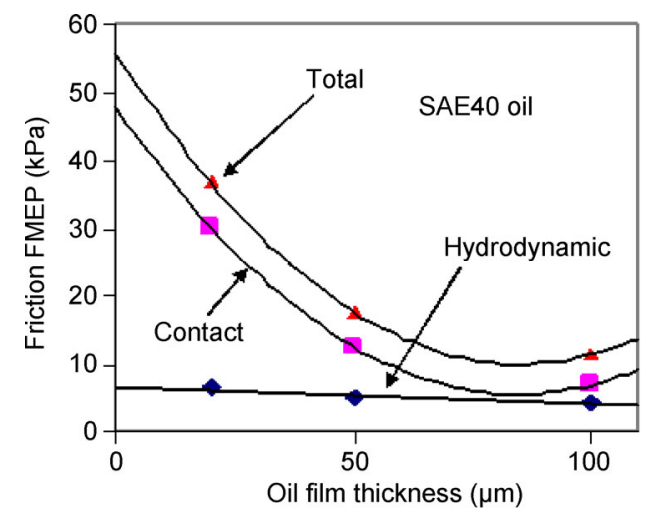

Fig. 6 Computations [14] showing effects of adequate upstream oil film thickness (oil supply) on piston-skirt friction for an 18-liter natural gas engine at $1,800 \mathrm{rev} / \mathrm{min}$ full load. Boundary contact friction diminishes rapidly as skirt is adequately lubricated. gasoline engines. Ring tension in the oil control ring is provided by an expander piece. The top ring, or compression ring, primarily seals the combustionchamber gas from leakage past the ring. This action is accomplished by the ring tension and combustion-gas pressure at the back of the ring. The function of the second ring, or scraper ring, is more intricate: First, the second ring performs additional sealing function and its face profile is shaped to scrap oil on the liner down, away from the combustion chamber. Furthermore, the second ring controls the inter-ring gas pressures, thus the flow of blow-by gases towards the crankcase or their reverse flow back into the combustion chamber. This subtle action is accomplished by the careful balance of a combination of design factors of the ring, such as ring twist (preferential bending and resulting contact with the ring groove), ring gap, mass and geometry of the ring. As the name implies, the oil-control ring controls the amount of oil available to the upper rings for adequate lubrication but minimum oil consumption.

The relative sliding speed between the rings and the liner varies substantially over the engine cycle, so does the lubrication regime for each of the rings. Boundary friction is dominant near the end strokes where the relative rubbing velocity is zero and oil film thickness minimal. Near the mid-strokes of piston travel, the reverse is true. While the exact proportion of boundary versus hydrodynamic friction varies with specific mechanical design and operating parameters, the oil-control ring is expected to operate preferentially 
with more boundary lubrication overall due to the high ring tension and the relatively small rails against the liner. In general, both the top-ring and the oilcontrol ring friction are significant, while the secondring friction is generally considered the smallest in the ring pack, due to the relatively lower ring tension and lower gas pressure behind the ring.

Although shown with rectangular cross sections in Fig. 3, various shapes of rings are used in practice. The keystone ring and groove, characterized by a non-rectangular groove for diesel engines, facilitates the removal of combustion residues due to the radial movement of the rings relative to the grooves. The running surfaces of rings are often coated with wearresistant materials. Significant engineering has gone into piston-ring designs; the following sub-sections can only cover the general lubrication and friction characteristics of the rings rather than their detailed design and engineering.

The following two sections on lubrication fundamentals in the piston ring pack (friction and gas dynamics) can be skipped, at the readers' discretion, and move directly to Section 2.4 without much loss in continuity.

\subsubsection{Lubrication and friction in the ring pack}

Fundamental ring-liner slider analysis: The basic understanding of ring-liner lubrication is shown conceptually by a slider arrangement shown in Fig. 7, where a slider executes a reciprocating motion relative to the liner. The radial load on the ring consists of the pressure force at the back of the ring in the groove acting perpendicularly towards the liner surface as shown, plus the ring tension that tends to expand the ring against the liner. A hydrodynamic pressure is generated in the oil film that, from hydrodynamic theory, strongly depends on the sliding speed of the barrel shaped wedge. The simplest form of the Reynolds equation, with surface roughness and other features omitted for simplicity, for the ring-slider is shown in Eq. (1), in reference to Fig. 7, where $x$ is the distance in the sliding direction, $h$ the film thickness, and $p$ the hydrodynamic pressure in the oil film, and $\mu$ the oil viscosity:

$$
\frac{\partial}{\partial x}\left(\frac{h^{3}}{\mu} \frac{\partial p}{\partial x}\right)=-6 U \frac{\partial h}{\partial x}+12 \frac{\partial h}{\partial t}
$$

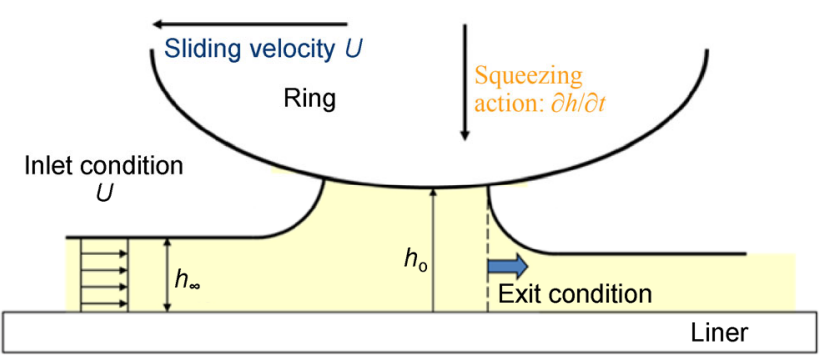

Fig. 7 Fundamental ring-liner lubrication and friction model.

To account for surface characteristics such as surface roughness, textures or waviness, flow factors [16] can be added that modify the first two terms in Eq. (1). The force balance of the radial load against the oil pressure, together with pressure and mass continuity boundary conditions at the wetted edges of the ring, determine the minimum oil film thickness. When the film thickness becomes small enough where boundary or mixed lubrication may occur, an asperity contact model [17] is commonly used to determine the boundary contact pressure, which will also take part in the radial force balance. Similar analysis is carried out for the second ring and for each of the rails of the oil-control ring. The film thickness on the liner left by the passage of one ring provides an inlet film thickness condition for the following ring or rail. The effects of any piston tilt or groove angle when the rings rests on the ring groove will be to change the relative orientation of the ring-face profile relative to the liner.

Friction behavior of individual rings: Obviously, the exact magnitudes of the film thickness of the rings and friction depend on the ring design parameters, surface characteristics, lubricant properties, and operating conditions. Figure 8 shows an example of predictions of ring-pack friction in an advanced reciprocating engine [18] that illustrates some basic features of ring-pack friction:

(a) Two types of friction power loss peaks occur in this illustration-(i) friction peaks periodically at midstroke which correspond to periods of high sliding velocity, as shown by the oil-control ring friction, and (ii) peak friction power loss around the top ring reversal position near top center, shown by the top ring. Upon closer examination, the peaks correspond to a high level of solid-solid contact in boundary lubrication. 


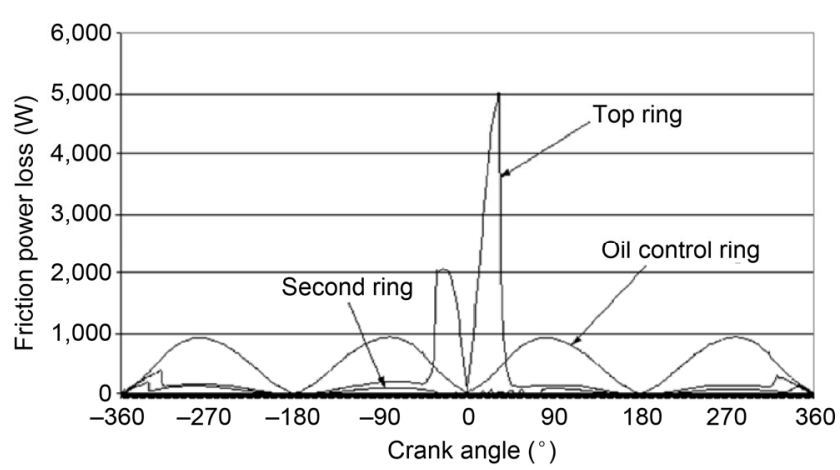

Fig. 8 Friction power loss contribution in the piston ring pack for an 18-liter natural gas engine at 1,800 rpm full load.

(b) The other general feature is that the magnitude of the second ring friction is significantly less than either that of the top ring or oil-control ring, primarily due to the subdued inter-ring pressure adding to the outward radial load on the ring against the liner.

\subsubsection{Ring dynamics and gas flows in the ring pack}

In addition to the radial forces of ring tension and gas pressure holding the rings against the liner, providing ring-liner seals, axial forces (gas pressure, inertia, and friction) also act on the rings, pressing the rings against the grooves surfaces, sealing the combustion gases from leaking around the rings in the grooves. The rings are carefully designed with a positive or negative twist angle (relative to the ring groove edges), as shown in Fig. 9, to control the point of sealing and the pressure distribution around the ring. The axial forces and moments determine the ring's axial motion and its tilt in the ring groove. These axial forces include primarily the gas pressure forces acting on the flanks of the ring-intricately controlled by the designed twist (static twist) - balanced against the inertial force on the ring due to the reciprocating piston motion. The rings typically sit flat on the bottom groove flank about three-quarters of the time on the top groove flank about a quarter of the time, due to the higher gas pressure on the combustion chamber side. There are two narrow time intervals, of a few crank angle degrees each, where a ring makes a transition from primarily one side of the groove towards the other. During ring transition, enhanced leakage of gases occurs. If the flow is towards the bottom towards the crankcase, there is increased blow-by. Reverse flow can also occur due to the inter

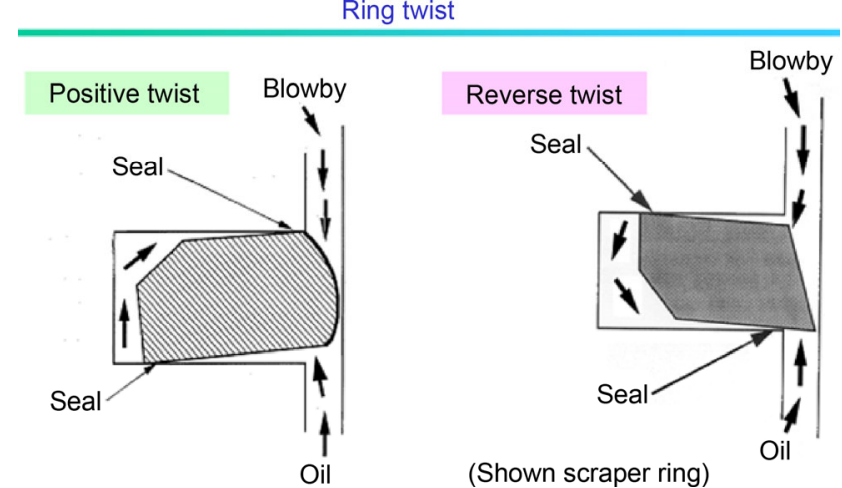

Fig. 9 Schematic illustrating positive and negative static ring twists.

ring pressure dynamics, when the cylinder pressure decreases faster than the reduction of inter-ring pressures. Oil consumption could increase when reverse flow occurs, either due to flow around the grooves or through the ring gaps.

\subsection{The crankshaft and connecting-rod bearing systems}

The lubrication modes at the main bearings of the crankshaft, at the connecting-rod/crankshaft interface (big-end bearings), and at the interfaces between the piston pin and the piston pin bosses, and between the connecting rod and the piston pin are all journal bearing lubrication. Hence categorically they are discussed under this section.

\subsubsection{The crankshaft main-bearing subsystem}

Journal bearing friction: Apart from its interfaces with the connecting rods, the crankshaft's friction comes primarily from the main bearings that support the crankshaft in its rotational motion. The bearing seals also generate some friction attributable to the crankshaft. The crankshaft rests on a layer of oil between the shaft and the outer bearing shell. The axis of the crankshaft is off center from that of the bearing center. This offset, called bearing eccentricity, generates the hydrodynamic pressure during shaft rotation. Oil is amply supplied to the bearing surfaces through oil feeds along the crankshaft. With adequate oil supply and under normal loads, the lubrication at the main bearings is primarily in the hydrodynamic regime. Journal bearing calculations usually apply the Reynolds equation, in cylindrical coordinates, to 
the lubricant in the journal bearing in determining the oil pressure distribution, the locus of the journal relative to the bearing surface, and thus the minimum oil film thickness. The minimum oil film thickness is an important design parameter and is usually kept larger than the surface asperity heights to avoid mixed or boundary lubrication. The dynamic loading originates from the rapidly varying cylinder pressure pushing against the piston and the connecting rod, and then to the crankshaft.

The friction in the journal bearing is proportional to the surface shear stress integrated over the entire bearing surface area. A dimensional analysis indicates the following functional dependence holds [12]:

Average shear stress $\approx \mu \pi D_{\mathrm{b}} N / h_{\mathrm{m}}$

where $\quad \mu$ is the oil viscosity;

$D_{\mathrm{b}}$ is the bearing diameter;

$N$ is the rotational speed;

$h_{\mathrm{m}}$ is the mean radial clearance.

Bearing surface area $\approx \pi D_{\mathrm{b}} L_{\mathrm{b}}$

where $L_{\mathrm{b}}$ is the bearing length.

Accordingly, the bearing friction,

$$
F_{\mathrm{b}} \approx \mu \pi^{2} D_{\mathrm{b}}^{2} L_{\mathrm{b}} N / h_{\mathrm{m}} .
$$

The mean oil film thickness, $h_{\mathrm{m}}$ in the journal bearing is a function of the applied loading and other geometric factors of the journal bearing and lubricant viscosity. Thus the friction scaling law for journal bearings often used is simply $[4,6]$ :

$$
F_{\mathrm{b}} \propto \mu D_{\mathrm{b}}^{2} L_{\mathrm{b}} N
$$

The proportionality constants are often empirically determined and are specific for a certain bearing design. Thus the connecting-rod/piston-pin bearing takes on a different proportionality constant from the con-rod big-end bearing, which is also different from that for the crankshaft.

Current research in journal bearing friction is obviously much more advanced than portrayed in the simple analysis above. Recent detailed computer simulations are able to predict friction very accurately, for example in references $[19,20]$.

Main-bearing seal and other friction: The bearing seal lips and the crankshaft surfaces are generally considered to be in constant solid-to-solid contact, with a constant friction coefficient, as in boundary lubrication, and a constant normal force, thus constant friction force. Obviously, the friction power loss from the seals is thus proportional to the rotational speed and the bearing diameter and the total contacting surface area. The proportionality constants depend on how tightly the seals are maintained and the surface characteristics of the surfaces. These constants, which vary from seal to seal, are determined empirically. Some researchers [6] consider another loss mechanism due to the power loss from pumping oil through the crankshaft oil feeds. However, strictly, this is not "rubbing" friction as discussed earlier in this article, but could actually be considered part of the accessories power losses.

\subsubsection{The connecting-rod subsystem}

The connecting-rod/piston-pin friction: The cylinder pressure force on the piston is transmitted to the crankshaft via the connecting rod, the top end of which connects to the piston via a piston-pin and pin-bosses that form part of the piston. Figure 10 shows the piston, pin, and connecting rod system. There are actually two sets of interfaces: (a) the bearing between the piston-pin and the small end of the connecting rod, and (b) the bearing between the piston-pin and the pin bosses. However, as in the crankshaft bearings, lubrication in either case is characterized as a dynamically-loaded journal bearing system. For high cylinder pressures - a trend in producing more power for given engine displacement-the pin/boss, pin/ connecting-rod bearing interfaces represent some of the most highly loaded areas in the engine. Since the

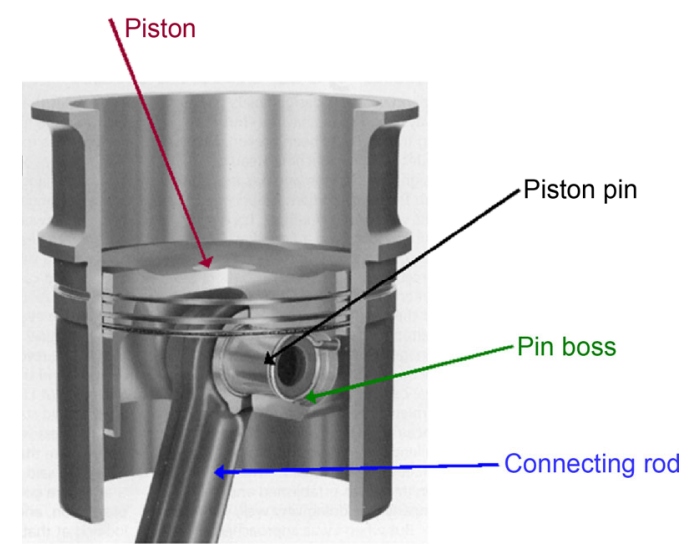

Fig. 10 Schematic of piston, piston-pin, and connecting rod, showing bearing interfaces. 
piston pin rotates very slowly [21], hydrodynamic lubrication of which is unlikely; in contrast, analyses assuming the more general condition of mixed lubrication have been used [22-24]. Some measurements of pin friction [25] also suggested mixed-lubrication; however, in those experiments the pin showed significant bending, perhaps partially responsible for the observed mixed or boundary lubrication. Assuming predominantly hydrodynamic lubrication, then the friction coefficient is roughly proportional to the term $\mu V / P$, where $\mu$ is the oil viscosity, $V$ is the relative speed between surfaces which is proportional to engine RPM, and $P$ is the load per unit area.

The connecting-rod/big-end friction: The connectingrod big end refers to the connection between the connecting rod and the crank. Lubrication here is also primarily in the hydrodynamic regime. Adequate oil is supplied to the bearing surfaces through feeds along the crankshaft. As in the case with crankshaft main bearing and piston-pin bearings, the bearing friction is proportional to the bearing surface area and mean linear velocity, which in turn is proportional to the bearing diameter at a given engine RPM.

For both the piston-pin and con-rod big-end bearing lubrication the friction is proportional to the square of the bearing diameter, $D_{\mathrm{b}}$, and the bearing length, $L_{\mathrm{b}}$, (i.e., $D_{\mathrm{b}}^{2} L_{\mathrm{b}}$ ). Earlier estimates indicate that connecting-rod bearing friction is comparable to but somewhat less than piston-skirt friction [4]. In view of the increasing trend of higher cylinder pressure (bmep) engine operation for improved efficiency, the contribution to total friction from the connecting-rod bearings could become more significant, especially when and if asperity contacts in the mixed lubrication mode begin to be felt. However, the design of an adequate lubricant flow to the bearings will keep solid-solid contact to a minimum.

An early analysis by Bishop [26] derived an expression for the crankshaft and connecting-rod journal bearing friction combined, where the additive terms from the various subsystems are apparent. The friction, normalized by the displacement volume ( $\propto$ bore $^{2} \times$ stroke), in the form of friction mean effective pressure (fmep), in $\mathrm{kPa}$, is given by [26, 27]:

Combined bearings fmep $=41.4(N / 1000)\left(D_{\mathrm{mb}}^{2} L_{\mathrm{mb}}+\right.$ $\left.D_{\mathrm{rb}}^{2} L_{\mathrm{rb}} / m+D_{\mathrm{as}}^{2} L_{\mathrm{as}}\right) /\left(B^{2} L\right)$ where: $N$ is the crankshaft rotational speed in rev/min, $B=$ bore, $L=$ stroke, $D_{\mathrm{mb}}=$ the main bearing diameter, $L_{\mathrm{mb}}=$ the total main bearing length divided by the number of cylinders, $D_{\mathrm{rb}}=$ the connecting-rod bearing diameter, $L_{\mathrm{rb}}=$ the total connecting bearing length, $m=$ the number of pistons per rod bearing, $D_{\text {as }}=$ the accessory shaft bearing diameter, and $L_{\mathrm{as}}=$ the total length of all accessory shaft bearings divided by the number of cylinders.

\subsection{Valvetrain system}

The valvetrain system consists of a series of mechanical parts that serve primarily to open and close the intake and exhaust valves. The valvetrain converts the rotary motion of the camshaft, at one end, to oscillatory motion of the valves at the other end. The cam lobes on the camshaft determine the valve timings. There are several prevalent configurations of the component layouts (primarily of the rocker arm) between the camshaft and the valves themselves, as shown in Fig. 11 [28]:

(1) Direct acting, overhead cam (OHC): Cam lobe on tappet directly, no rocker arm.

(2) End-pivot rocker arm, overhead cam ( $\mathrm{OHC})$ : Cam lobes drives follower between pivot and valves.

(3) Center-pivot rocker arm:

(a) Overhead cam (OHC); cam lobe acts on end of rocker arm directly.

(b) Overhead cam (OHC); cam lob acts on end of rocker arm via lifter.

(c) Cam in block, overhead valve (OHV), cam lobes acts on rocker arm via extended pushrod.

These configurations differ in simplicity, the number, size, and mass of the parts involved, and thus the stiffness of the system, which determines how fast the response of the oscillatory valve motion follows the actuating cam motion. They also differ in size/packaging and inertia, and thus their suitability varies depending on specific engine applications.

Tribological contacts and sources of friction: There are four main categories of contacts and sources of friction in the various configurations of valvetrains described above. The lubrication modes range from predominantly hydrodynamic to boundary lubrication and mixed lubrication. The major contact and friction categories are: 


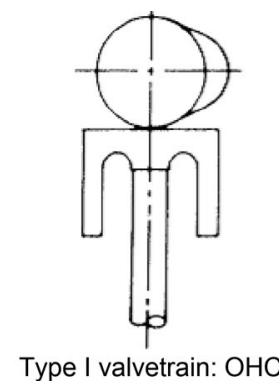
direct-acting

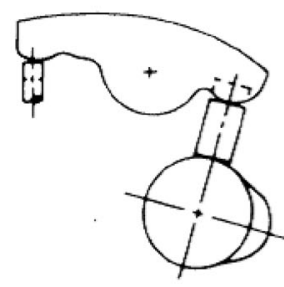

Type IV valvetrain: $\mathrm{OHC}$ center pivot rocker arm with cam follower

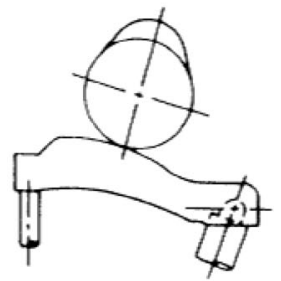

Type II valvetrain: $\mathrm{OHC}$ end pivot rocker arm

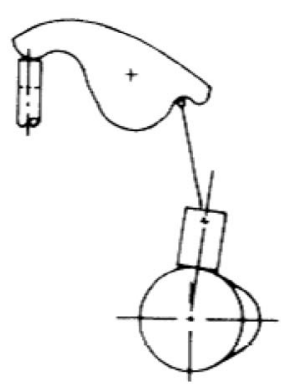

Type $\vee$ valvetrain: cam in block center pivot rocker arm with push rod

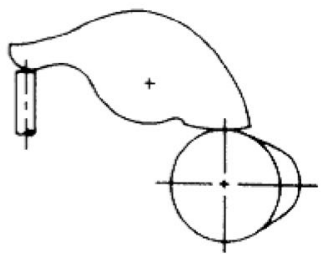

Type III valvetrain: $\mathrm{OHC}$ center pivot rocker arm

$\mathrm{OHC}=$ overhead cam

Fig. 11 Major types of valvetrain configurations [28].

(1) The camshaft bearing friction: The camshaft is supported by camshaft bearings similar to the crankshaft main bearings. The applied bearing load on the camshaft is significantly less than the load from the cylinder pressure through the connecting rod to the crankshaft. The journal bearing lubrication at the camshaft bearings is mostly hydrodynamic. Estimates of the percentage contribution to total valvetrain friction from camshaft bearings varies from $12 \%$ or higher in earlier estimates [28, 29], as shown in Fig. 12, to up to $12 \%$ in more recent estimates [30]. In reality, its relative contribution is a function of engine speed and it depends on the magnitude of the other components, specifically that of the cam followers.

(2) The cam/follower interface friction: The camfollower interface can be the cam lobe against a flat follower or a roller follower. In the flat follower configuration, the local load, film thickness and friction vary with the relative position of the cam lobe to the follower. At the tip of the lobe, the local load is high and concentrated in a small area, and boundary lubrication is dominant. For the rest of the cam-follower contact, mixed lubrication prevails. The cam/follower interface is often modeled as a narrow elliptical or line contact from which the contact pressures are calculated. In the mixed lubrication regime, the viscosity of the lubricant depends on the pressure and elastohydronamic lubrication is assumed. Friction in the cam/flat-follower interface, consisting mostly of boundary-contact friction and some viscous drag, contributes to most of the valvetrain friction [30]. Roller followers, however, significantly reduce the cam/follower friction recently, by an order of $50 \%$ or better [31].

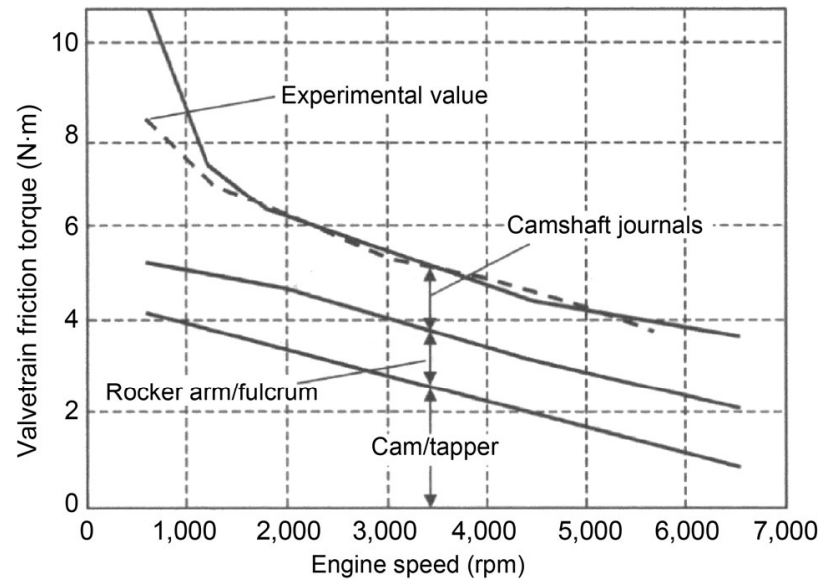

Fig. 12 Effect of engine speed on valvetrain friction components for non-friction modified SAE 30 oil at $100{ }^{\circ} \mathrm{C}[28,29]$. 
(3) The rocker arm pivot/shaft friction: Similar to the crankshaft seals, lubrication at the rocker arm pivot/shaft interfaces is mostly boundary lubrication. This is also due to the fact that there is very little lubricant supply to the surfaces. The boundary friction force at these interfaces is proportional to a constant friction coefficient and the applied contact load. Overall, friction at the rocker arm pivots can be as low as $10 \%$, as Fig. 12 shows at low speeds. Obviously, this percentage depends on the friction in the other components, which have come down as well in recent years, making the rocker arm pivot/shaft friction not negligible.

(4) Friction in linearly oscillatory components: The components in the valvetrain in this category include the valve stem and seals, valves and guides, valve lifter and lifter bore-components that experience relative reciprocating or oscillatory motion. When the velocity in the oscillatory motion is small, we assume boundary lubrication. In general, the oscillatory motion, similar to the piston rings against the liner, also shows hydrodynamic lubrication at higher speeds during parts of the oscillatory motion. Both experiments and computations show that the percentage of valvetrain friction contributed from oscillatory motion is of the order of a few percent [30].

Valvetrain friction has been studied in great detail computationally and by experiments [32]. Typically, the reported contribution of valvetrain friction to overall engine mechanical losses is of the order of $15 \%-20 \%$, although estimates of valvetrain friction as high as $40 \%$ have been reported [33]. Valvetrain friction is relatively more significant at lower speeds, indicating that most of the valvetrain friction comes from boundary and mixed lubrication.

\subsection{Engine friction reduction by surface textures or coatings}

In addition to friction and wear control by the micro-design of engine component geometries and configurations, as described in the previous sections, friction and wear can also be controlled via the use of surface texturing or coatings. While coatings protect the surface from abrasive wear through the hardness of the material, surface texturing affects the friction and wear of the surfaces in intricate ways, and is the focus of the discussion in this section.

Takata et al. [34] provided a succinct introduction to the topic: Texturing has been recognized as a method for enhancing the tribological properties of sliding surfaces for many years. Early studies recognized the potential of micro-asperities to provide hydrodynamic lift during film lubrication [35-37], while more recently renewed interest in the role of surface texturing has yielded analytical and experimental results that reveal more detail about the mechanisms by which surface features influence lubrication and friction. Like large scale converging surfaces, micro-scale asperities can create an asymmetric oil pressure distribution that results in hydrodynamic lift. In the case of mixed lubrication, this added lift can alter the balance between hydrodynamic and boundary lubrication, reducing the amount of asperity contact that takes place, and thus reducing both friction and wear. Also, even when contact does not occur, an increase in oil film thickness reduces shear within the oil, reducing hydrodynamic friction. Several studies, both analytical and experimental, have considered the effects of surface patterns in well-lubricated cases.

Because they can assist in creating hydrodynamic pressure in the fluid film, textured surfaces have an effect on the lubrication regime of sliding surfaces. Kovalchenko et al. [38] looked closely at the lubrication regime in a series of experiments using a pin-on-disk test rig with unidirectional sliding, producing Stribecklike curves for various textures and conditions. In general, adding surface dimples expanded the range of parameters under which hydrodynamic lubrication took place, extending the non-contact regime to low speeds and viscosities. Sadeghi and Wang [39] have also demonstrated that texturing can reduce asperity contact, analytically showing that adding dimples in the end-stroke region of a reciprocating slider can reduce contact in this area.

Several studies have also shown that friction can be reduced with the addition of surface dimples even when no contact occurs. Ronen et al. [40] have completed several analytical and experimental studies considering the effects of round dimples on sliding friction and load support. Analysis of "piston-ring like" cases showed that adding dimples to one surface could 
decrease friction in reciprocating sliding due purely to hydrodynamic friction reduction (asperity contact was not considered in the model). Reciprocatingslider testing also showed reduced friction for welllubricated cases. Other results, though, suggested that the texturing could be harmful in poorly-lubricated situations [40, 41].

Many other studies, both analytical and experimental, have studied the effects of surface texturing. Siripuram and Stephens [42] as well as Hsu [43] considered the effects of different dimple shapes. Siripuram and Stephens [42] considered circular, square, diamond, hexagonal and triangular cross-sections, and concluded that friction reduction was generally independent of shape. Hsu [43], however, concluded that dimple shape could have some effect, and that, in particular, shapes with an orientation more perpendicular to the sliding direction could delay the onset of asperity contact. Other researchers have also predicted that texture orientation has an effect on friction and oil film thickness. Michail and Barber [44] predicted increased oil film thickness for textures more perpendicular to the sliding direction, while Jocsak et al. [45] also predicted increased film thickness and reduced friction for lower honing groove cross-hatch angles (grooves more perpendicular to the sliding direction).

Takata et al. [34] also showed in Fig. 13 the friction losses of three example surface textures, as compared to the baseline. For the baseline case the cylinder liner is un-textured. The viscosity temperature dependence was kept the same as overall viscosity was changed. The figure also shows that adding the surface texturing alone results in friction reduction in all cases, and then

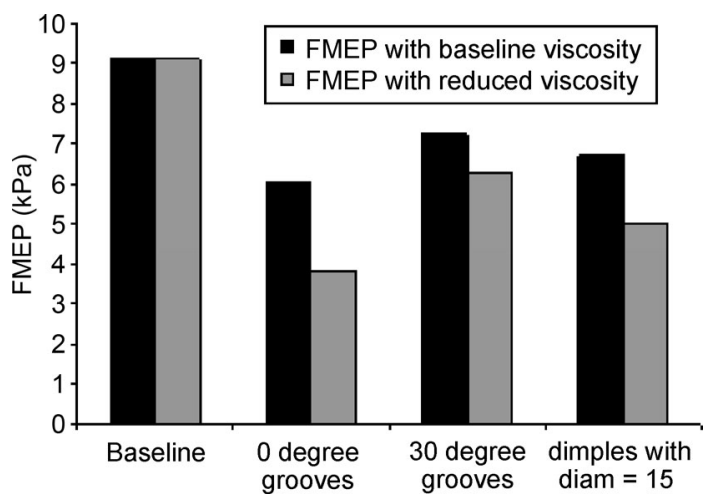

Fig. 13 FMEP reduction due to combined lubricant and surface texturing effects. additionally reducing the lubricant viscosity causes friction to decrease further. Also, the reduction due to reduced lubricant viscosity is approximately proportional to that due to the texturing alone.

Figure 14 shows the corresponding effects of the combined surface/lubricant optimization on wear, shown by a wear parameter which is calculated as the boundary contact force integrated over the sliding distance. If viscosity is reduced without any surface texturing, a large increase in wear is predicted. Optimizing the liner surface texture and lubricant viscosity concurrently offers the opportunity to mitigate these negative side effects, while still substantially reducing ring/liner friction.

\subsection{Summary of engine component design on friction and wear reduction}

Categorically, there are three major approaches to reduce friction and wear in an engine: (a) through mechanical design of the detailed micro-geometries, configurations, and properties of the major component. These include those in the power cylinder, which contribute to approximately half of all the friction losses. Besides the power cylinder components, the bearings and valve-train components share the remainder of the frictional losses, the proportion between valve-train and bearing losses depends on the specific design of the engine. These two systems do contrast completely different in that metal to metal rubbing is dominant in the valve-train system where hydrodynamic lubrication is the norm in the

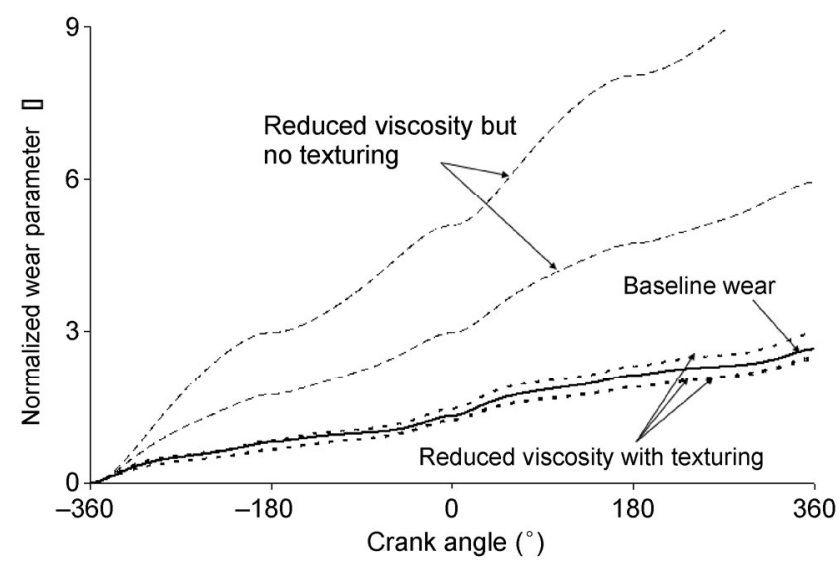

Fig. 14 Normalized wear parameter, for combined surface/ lubricant effects. 
crankshaft and camshaft bearings. Such behavior has impact on the relative effects of lubricant and material properties, such as coatings, surface texture, and lubricant viscosity on friction of wear. Hence, the other two approaches to friction and wear control, besides mechanical design are: (b) through surface engineering and coatings, and (c) lubricant and additive technologies. This section focuses discussion on mechanical design and surface effects, while lubricant and additive effects are covered in a separate section.

Concerning engine wear, due to the higher metalto-metal contacts in the valve-train system, wear is more sensitive to the mechanical load between contacting surfaces, such as cam lobes. Likewise reducing lubricant viscosity, as in the new trends for low-friction oils, tends to reap its benefits in the power-cylinder components and the bearings.

Surface texturing affects the flow between the surfaces with net results similar to the change in lubricant viscosity. However, reducing friction with surface texturing has the benefit of not increasing wear, comparing to reducing viscosity alone. More details concerning lubricant and additive effects will be discussed in subsequent sections.

\section{Fuel economy improvement and green- house emission reduction by emerging engine technology}

\subsection{Gasoline engine improvement}

The emerging technology in today's engines, as shown in Fig. 15, has created a deep impact to improve fuel economy and reduce greenhouse emissions. These emerging technologies incorporate (1) modular and flexible architectures, (2) reduced mass, (3) improved combustion technology, (4) improved turbo-charged engines, and (5) integration of leading edge technologies. In the early 1990s, most new light vehicles had replaced carburetors with indirect fuel injectors, sometimes called port-fuel injection (PFI). With PFI, the air and fuel are mixed in the intake manifold and controlled by computerized electronic control units (ECUs). However, additions such as turbocharging, variable-valve timing (VVT) [46], and direct injection were still rare and considered high-cost performance
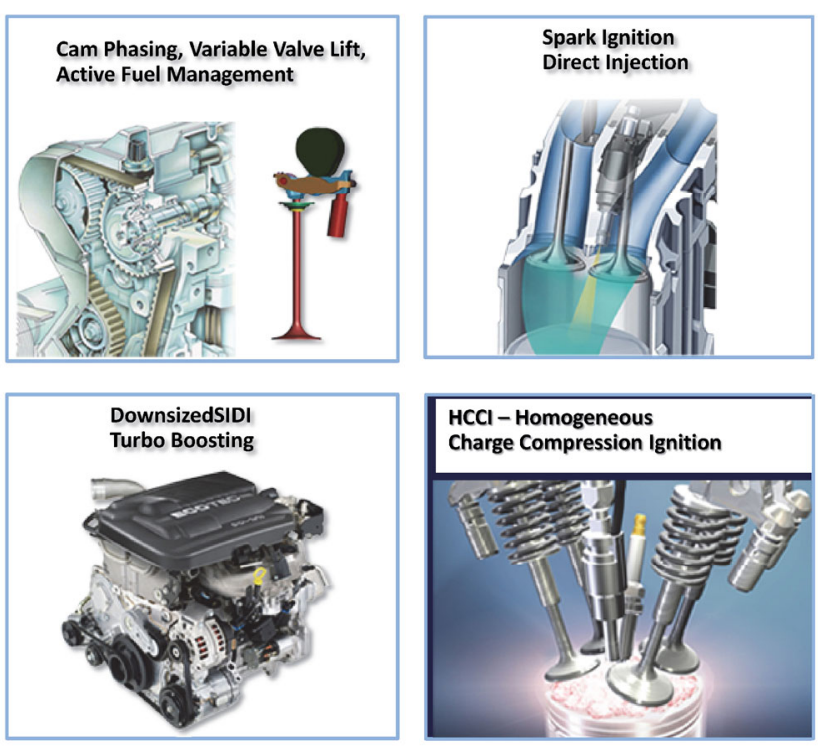

Fig. 15 Improving gasoline engine technologies.

features. Direct injection uses high-pressure fuel injectors to spray a fuel mist directly into each cylinder, where it is mixed with air and ignited. This improves the engine's transient response and increases engine efficiency. Direct injection enables greater compression ratios, which also improves fuel economy. VVT is a technology that changes the timing of the valves during intake and exhaust as the engine RPM changes, increasing the efficiency of the engine.

A turbocharged engine design consists of two turbines connected by a shaft [47]. One turbine is driven by the exhaust gases from the engine, while the other is placed within the intake system and compressing the incoming air. Recently several OEMs reported that turbocharging operation under higher temperatures and higher rotational speeds can form high-temperature deposits, bearing material seizing and overheating. The relentless drive to improve engine efficiency and performance has led to the development of small turbocharged, gasoline direct injection (TGDI) engines. As governmental regulations on emissions and fuel efficiency become increasingly more stringent worldwide, original equipment manufacturers are using TGDI to improve fuel efficiency and reduce carbon dioxide emissions versus comparable port fuel injection technology, while maintaining or improving power output and performance. These engines feature increased power density, squeezing 
more performance out of a smaller package. However, they have the adverse effect of running hotter and harder than conventional engines, placing the oil under more stress. The higher temperatures, often combined with higher fuel dilution, can lead to oxidation, oil thickening, deposits and sludge. Studies show that fuel quality is critical to the reliable operation of TGDI engines [47]. This is a particular concern when these engines are introduced to developing countries. Although fuel in major urban areas is well controlled, the quality in many outlying areas can be very poor, containing more so called "heavy ends" and sulfur. These constituents lead to increased fuel dilution and acid generation compared to high-quality fuel, causing significant oil degradation. Under these operating conditions, severe deposits can form on some of the very hot surfaces within the engine, such as those within the turbocharger bearing housing, and lead to bearing failure. In addition to these hard deposits, the increased oxidation can generate significant sludge that blocks filters and oil galleries. Fortunately, engine oil formulators have a lot of additive options to meet these challenges.

In a GDI engine [48], gasoline is injected directly into the combustion chamber, rather than into the intake port. This arrangement provides significant benefits in power and efficiency over the traditional engine. Powertrain engineers are looking for possible remedies such as a new bearing design to support the common shaft between the turbines for reducing friction heat. Lubrication for these engines needs to have a resistance to forming high-temperature deposits, primarily to prevent turbocharging bearing from seizing, and resistance to oil aeration. GDI engine technology has the following impact on future energy efficiency and lubrication requirements:

Multi-port fuel injection (MPFI) combustion

- Homogeneous mixture of air and fuel.

- Uniform combustion results in few "soot" particles.

- Energy efficiency is lower compared with GDI combustion due to lower injection pressure.

GDI combustion

- Non-homogeneous mixture of air and fuel resulting in partially burned fuel and high concentrations of soot over MPF.

- GDI created more "soot" particulates, up to $10 \mathrm{x}$ more soot over MPF.
- Boosted engines PCV system trap exhaust gas which leads to more acids in the oil resulting in oil degradation. More advanced additives are needed to prevent oil degradation.

\subsection{Diesel engine improvement}

In general diesel engines are more efficient than gasoline engines. Diesel engines typically run at higher compression ratios, use lean mixtures, and exhibit fewer internal losses. They also use a fuel that contains about $11 \%$ more energy per gallon than gasoline. All diesel engines inject fuel directly into the cylinder. The major difference is that compressing the fuel/air mixture auto-ignites the fuel. All diesels used for light-duty vehicles through 2010-2014 were direct injection and turbocharged [46]. A major drawback of diesel engines compared to gasoline engines is that diesel engines tend to generate more emission problems. Diesel fuel is injected directly into the cylinder and never mixes thoroughly before and during ignition. Burning pockets of rich fuel induce soot formation. Lean pockets form $\mathrm{NO}_{x}$ at higher combustion temperatures. Because of this emission issue, extensive after-treatment is needed. With new emissions regulations in both North America and Europe looming, as shown in Fig. 16, additional equipment for diesel after-treatment such as catalytic converter, particulate filters and exhaust gas recirculation, will need to be added in the diesel engine. Many of the emerging technologies, as shown in Fig. 17, include two-stage turbochargers, downsizing engines and increasing boost pressures. In diesel engine technology, the following

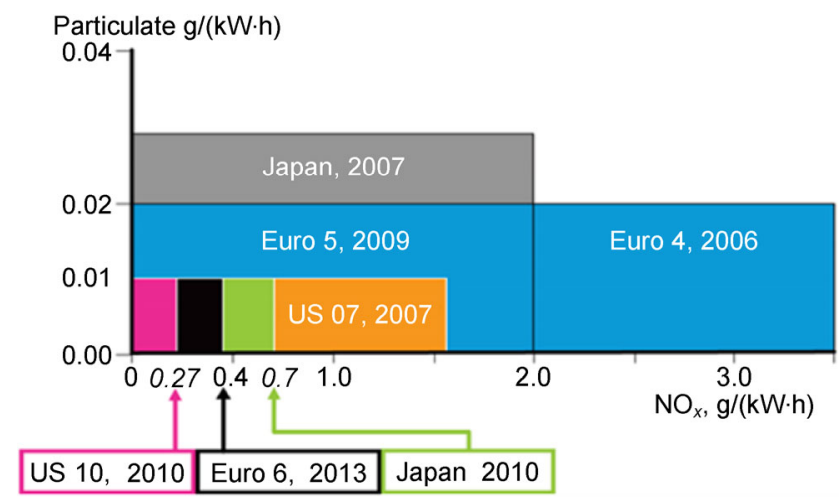

Fig. 16 On-highway emission standards for E.U., U.S. and Japan. 


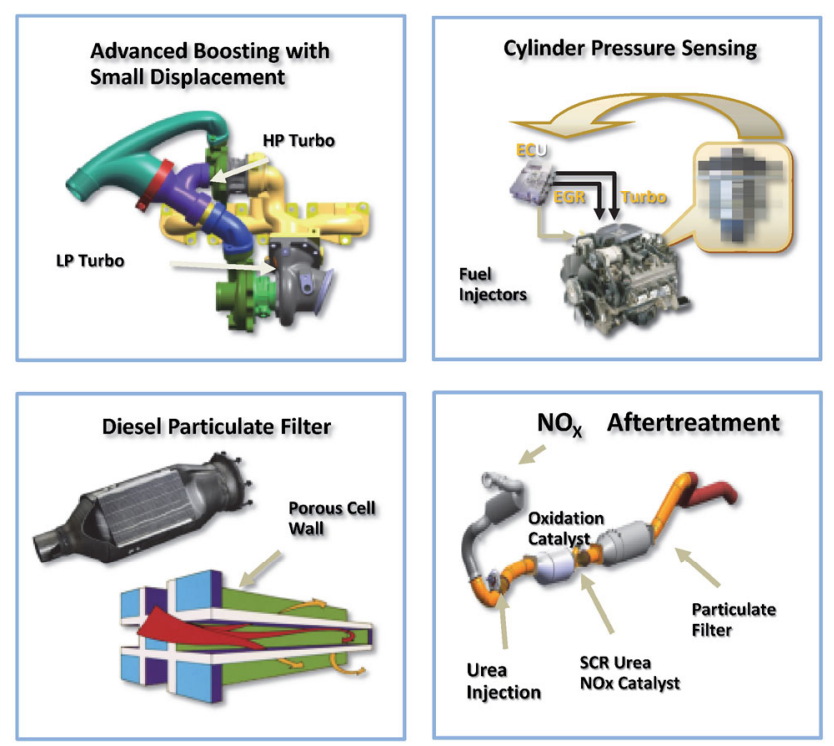

Fig. 17 Improving diesel engine technologies.

areas have been improved for boosting fuel economy and reducing emissions by after-treatment devices:

- High pressure injection.

- Lower compression ratios.

- Lean burn technology.

- Higher peak cylinder pressure.

- Advanced after-treatment technologies.

- Diesel particulate filter.

- $\mathrm{NO}_{x}$ after-treatment device using selective catalyst reduction (SCR).

Besides the above advanced gasoline and diesel engine technology, new engine innovations have been developed for enhancing the combustion process and improving fuel economy and after-treatment as follows:

\subsubsection{Engineering best compression ratio}

Recently more advanced engine control technologies have been developed. For example, powertrain engineers developed the best compression ratio [48, 49] to match a variety of engine speeds and loads. Higher loads require lower compression ratios to be more efficient. There are a number of different approaches to this control process such as advanced valve timing. This technique has eliminated the need for camshafts connected to the crankshaft to open and close the intake and exhaust valves. Electromagnetic, hydraulic, pneumatic, or some combination of valve actuators, are all possibilities. Common problems that could occur with these systems include high power consumption, reduced accuracy at high speed, temperature sensitivity, weight and packaging issues, high noise, high cost, and unsafe operation in case of electrical problems. Durability is another issue.

\subsubsection{Lean burn technology}

A special technique named lean burn $[50,51]$ was developed using more air than is required to burn the fuel in an engine. This is in contrast to most spark-ignition (SI) engines on the road today, which use just enough air to burn the fuel completely. This "just right" mix, termed stoichiometric, is 14.7 parts air to one part gasoline. The ratio for stoichiometric SI engines is sized for maximum power and acceleration. For them to run at less than their maximum power and maintain stoichiometric combustion (required by the catalytic pollution control system) requires a throttle on the intake air to reduce the airflow to the engine in proportion to the reduced fuel flow for lower-power operation. However, partially closing the throttle leads to inefficient operation at low loads. It takes more work to pump air through a partially closed throttle, known as throttle losses. Lean burn offers the possibility of reducing the throttling losses by controlling load with the amount of fuel injected, instead of throttling the intake air under part-load conditions.

The major issue with lean burn is that the common three-way catalyst cannot tolerate excess oxygen in the exhaust stream and still reduce $\mathrm{NO}_{x}$ properly. Three-way control technologies are designed to work with carefully controlled ratios of unburned hydrocarbons, carbon monoxide, and $\mathrm{NO}_{x}$. As long as these species are kept at the correct proportion, TWC efficiencies after light off are so high that the total engine-out emissions are not very sensitive. However, lean-burn operation, having excess oxygen in exhaust, would require more expensive exhaust after-treatment systems similar to diesels, such as lean- $\mathrm{NO}_{x}$ traps (LNT) or selective catalytic reduction (SCR). Since the cost of operating these systems is directly proportional to the amount of $\mathrm{NO}_{x}$ being produced (reagents or reductants), it's important to minimize engine-out $\mathrm{NO}_{x}$. One way to minimize the amount of $\mathrm{NO}_{x}$ created in lean-burn engines is by reducing the maximum temperature of the combustion process. 


\subsection{Major effects of additives on friction and wear}

The effects of additives on engine components depend on the lubrication regimes at the prevailing conditions at the local contacts. The lubrication regimes at the various components under most warmed-up conditions are: hydrodynamic (for bearings), mostly boundary (for valvetrain, cam-follower), and mixed for the piston/ring-liner interface except around the mid-stroke of the piston travel, where significant hydrodynamic lubrication is expected in most cases. There are variations among the different rings and the piston skirt surfaces, however. Accordingly, the effectiveness of the different additives-viscosity modifiers versus friction modifiers-varies at the different components and operating conditions.

Lubricant formulation affects friction primarily via (a) viscosity control-base oil selection and V.I. improvers, which can change the shear and temperature dependency of the viscosity, and (b) (boundary) friction modifier additives, which affect the boundary friction by forming surface layers with low shear strength.

\subsubsection{Lubricant/additives effects on engine emission-control system}

While lubricants and additives perform vital functions in an engine, the lubricant-derived emissions have serious impact on the exhaust after treatment system. For gasoline engines, the three way catalyst (TWC) has been around for close to 40 years, and strong evidence now exists showing that significant levels of phosphorous from engine oils can deteriorate the TWC prematurely. Since 2007, world-wide diesel regulations have been in place that mandate particulate emission levels that essentially need to be met utilizing diesel particulate filters (DPF). Since 2011, use of $\mathrm{NO}_{x}$ emission after treatment devices-mostly selective catalytic reductions (SCRs) for heavy-duty diesels and lean $\mathrm{NO}_{x}$ traps (LNT) for light duty diesel engines-have also become widespread in the US, Europe, and Japan. Figure 18 shows an schematic of such after-treatment emission control systems.

Lubricant derived compounds in the exhaust that affect the emission-control after treatment system include incombustible ash from metallic lubricant additives; and sulfur and phosphorus compounds.

Ash is problematic because it can build up inside the channels of diesel particulate filters (DPF). Unlike soot, ash cannot be oxidized into gaseous species. In as little as 35,000 miles, there is more ash accumulated in a DPF between regeneration intervals (for active regenerations) than soot [50]. The ratio of ash to soot in the DPF is even higher for continuously regenerated DPFs.

Over the last several years, lubricant specifications have been in place to limit the sulfur, phosphorus, and ash levels in lubricants, as well as volatility limits in the CJ-4 oil category [36]. The American Petroleum Institute (API), the European Automobile Manufacturers Association (ACEA), and the Japanese Automotive Standards Organization (JASO) have all introduced new "low ash" heavy-duty diesel engine oil specifications.

Significant studies have been conducted to characterize the ash compounds in the DPF. It has been shown that the engine back pressure doubles in about
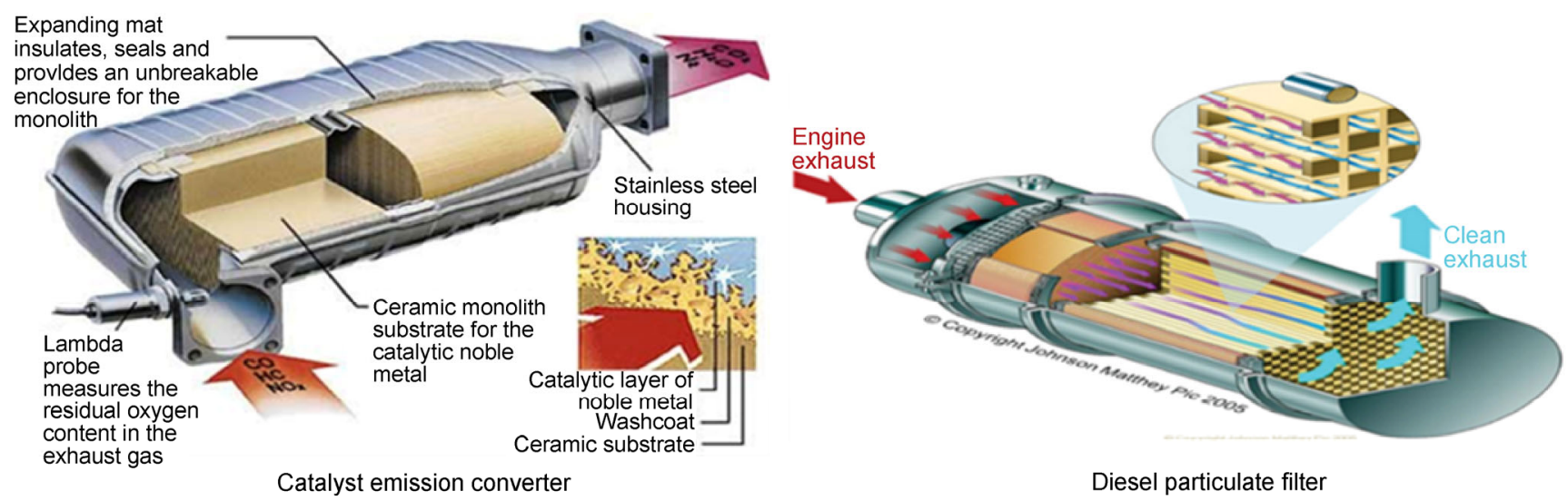

Diesel particulate filter

Fig. 18 After-treatment device function and construction. 
180,000 miles of normal operation [51], and that the type of lubricant additive seems to have a difference in how DPFs are affected $[52,53]$.

Lubricant-derived sulfur compounds affect lean $\mathrm{NO}_{x}$ trap (LNT) performance, as $\mathrm{SO}_{2}$ does compete with $\mathrm{NO}_{x}$ for storage sites in the LNT system. However, de-sulfation cycles can be designed that will drive the occupation of catalyst sites by $\mathrm{SO}_{2}$. However, the repeated high temperature de-sulfation cycles could compromise the DPF substrate integrity in the long term. It is not clear that phosphorous chemically interferes with conversion efficiencies of $\mathrm{NO}_{x}$ reduction systems. However, phosphorous affects the catalytic operation of diesel oxidation catalysts (DOCs) which are important in the conversion of $\mathrm{NO}$ to $\mathrm{NO}_{2}$-a step which is important in both $\mathrm{NO}_{x}$ reduction and soot oxidation.

Tremendous efforts are continuing to understand the characteristics of the lubricant-derived compounds in the emission after treatment systems, so that optimum formulations of lubricants and additives can be further developed that meet the simultaneous requirements of emission control and adequate engine protection.

\subsection{Lubricant composition and engine performance}

\subsubsection{Base oils}

Mineral base oil is typically derived from heavier hydrocarbons during the refining process. Synthetic base oil is synthesized from highly processed chemicals beyond those directly from the crude-oil refining stream. Some base oils being studied use exploratory fluids such as ionic liquids [54] and synthetic base stocks [55]-e.g., water based ionic liquids and some environmentally-friendly biological base lubricants use biodegradable base stocks [56].

The most significant performance parameter of base oils is the viscosity. The oil viscosity characteristics include the sensitivity of changes in the viscosity to temperature, such as the viscosity index, or V.I. lubricants tend to decrease in viscosity as temperature increases, and increase in viscosity as temperature decreases. ASTM D 2270 provides formulas for quantifying the V.I. given kinematic viscosities at 40 and $100{ }^{\circ} \mathrm{C}$. A high V.I. means a lubricant does not thin out much as it heats up nor becomes too thick at cold temperatures. These characteristics are important to ascertain so that the oil film does not become too thin at peak engine loads. The same oil also cannot be too thick to hamper its circulating freely around the engine during low-temperature start-up operation. Another important characteristic is the dependence of the oil viscosity on shear rate measured by the relative velocities and film thickness between moving parts. Specifications for the limits on the viscosities of the oil, including the high-temperature high-shear viscosities, at low temperatures and high temperatures, are given in the Society of Automotive Engineers (SAE) oil grade classification system [49]. Oils exhibiting viscosity adjustments at high and low temperatures are considered "multi-grade" oils [49]. By carefully controlling the engine oil-film temperature via strategic thermal management techniques (such as by increased or decreased cooling of the liner), piston-liner friction can be affected $[13,57]$. Computations show friction reductions of $20 \%-30 \%$ by increasing the temperature of the oil in the mid-section of the liner [58].

For mineral oils, the major classes of heavy distillates deriving from the crude oil for the lubricant are paraffinic or naphthenic hydrocarbons. Paraffinic oils can show high V.I., (VI higher than 100) while naphthenic oils can show low V.I. (VI lower than 100, for example between 80 to 100). Depending on the relative composition of the base oil, the V.I. can vary. The American Petroleum Institute (API) designates different groups of base oils based on the level of saturates and sulfur in the oil, and the V.I. Groups I, II and III represent increasing level of saturates (either below, or over 90\%), decreasing sulfur (either greater than $0.03 \%$, or less than $0.03 \%$ ), and increasing V.I. (between 80-120, or over 120). Group IV represents polyalphaolefins (PAO), and Group V represents all others, such as polyalkylene glycols and esters [49].

It is becoming increasingly more difficult to formulate modern engine oils with Group I base oils. A common practice is to combine Group I oils with Group III oils or PAO's. However, the introduction of significant levels of Group 1 oils becomes problematic due to their high volatility and high levels of sulfur. Thus it is becoming more common to use exclusively Group II oils. For high quality or top tier lubricants Group III oils and PAO's are used. 


\subsubsection{Additives}

Additives are materials added to the base oil to improve the performance or properties of the oil. There are typically 10-15 additives in the engine oil [59]. A great deal of literature has been published on lubricant additives. Reviews are available covering antioxidants, corrosion inhibitors, viscosity index improvers, friction modifiers and anti-wear additives [60]. These additives perform different functions, such as to reduce friction and wear, maintain engine cleanliness, or to improve the fluid properties, such as pour point or anti-foam properties. The most common engine oil additives are dispersants, detergents, anti-wear additives, antioxidants, friction modifiers, corrosion inhibitors, rust inhibitors, pour point depressants and viscosity index modifiers. Of these, the viscosity modifiers, friction modifiers and antiwear additives are the most important for designing robust engine oils that can prevent premature wear and provide friction reduction for improvements in fuel economy. Many anti-wear additives and friction modifiers contain metallic, sulfur and phosphorus chemistries that could adversely affect the emission after treatment system operation. In this review only the additives that effect friction and wear will be discussed as these directly impact engine oil fuel economy and robustness.

\subsubsection{Viscosity index (V.I.) improvers}

V.I. improvers are additives, typically high molecularweight polymers, added in small quantities to the base oil to reduce the temperature sensitivity of oil viscosity. As discussed in the section on base oils, a high V.I. is needed to ensure that the oil does not become too thin at high operating temperatures nor too thick for start-up and low temperature operations. Without V.I. improvers, the viscosity of most mineral oil base stocks increase sharply with a decrease in temperature. Generally, V.I. improvers are added to suppress viscosity increase at low operating temperatures and enhanced viscosity increase at elevated temperatures. Typical V.I improvers are olefin co-polymers (OCP), polymethacrylates (PMA), conventional and star hydrogenated styrene-isoprene copolymers, and styrene-butadiene co-polymer, and some exhibit supplemental dispersancy properties as well $[59,61]$. The proper selection of V.I. improver is important when developing fuel efficient engine oil. V.I. improvers must have sufficient shear stability so that they do not degrade and lose their effectiveness during use. In recent years PAMA dispersant V.I. improvers have shown utility to reduce friction in the boundary and hydrodynamic lubrication regimes [62]. They do this by minimizing viscosity increase at low temperatures. This reduces viscometric drag between the engine surface and the lubricant thus reducing heat buildup. This is done without compromising the high temperature properties of the lubricant. Thus the lubricant can maintain lower viscosities at low temperature for fuel economy benefits while still maintain higher viscosities at higher temperature for acceptable lubrication and wear protection.

\subsubsection{Friction modifiers}

Friction modifiers in crankcase oils are designed to reduce friction in the mixed or boundary lubrication regimes. These friction-reducing additives function by forming a slippery layer on the surfaces, and the layers have very low shear strength thus produce a low friction coefficient.

In general there are two types of friction modifiers used in engine oils. The surface active friction modifier types are long-chain hydrocarbon molecules with polar heads that anchor to the metal surface producing a sacrificial slippery chemical film that functions to reduce friction. These materials are commonly called organic friction modifiers. Examples of which are oleamide, boronated ester/amides and glycerol mono-oleate (GMO) [63]. Figure 19 shows examples of organic friction modifiers. The chemically reactive friction modifier types are organo-metallic molecules that function by reacting with the metal surface to produce a tribo-film with elastic properties that are highly effective at the proper temperatures and pressures for reducing friction. These materials are generally based on organo-molybdenum chemistry and include molybdenum dithiocarbamates, trinuclear organo-molybdenum compounds, molybdate esters and molybdenum thiophosphates [64]. Figure 20 shows examples of metallic friction modifiers.

One important aspect of organo-molybdenum-based friction modifiers is that under certain conditions 


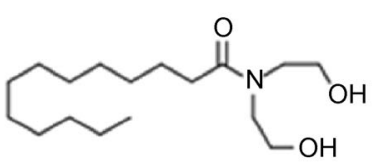<smiles>CCCCCCCC/C=C/CCCCCCCC(=O)OCC(O)CO</smiles>
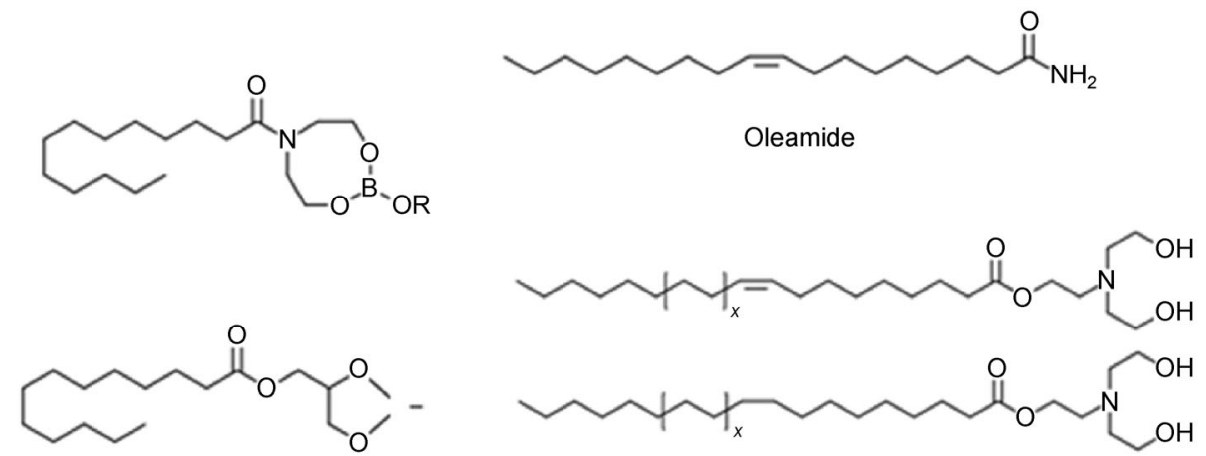

Fig. 19 Organic friction modifiers.
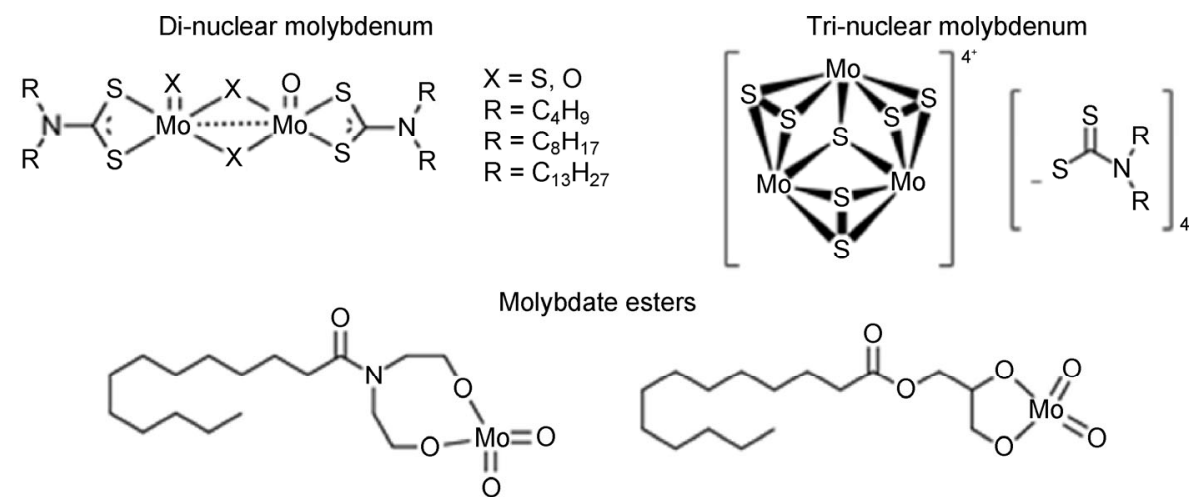

Fig. 20 Metallic friction modifiers.

they can also provide improvements in oxidation control and wear protection. This makes the organomolybdenum-based friction modifiers of particular value in modern engine oil formulations since they are multi-functional. Many examples exist where organo-molybdenum compounds are used exclusively as antioxidants or anti-wear additives $[65,66]$. Thus this class of friction modifiers is finding great versatility to solve a wide range of engine oil formulation challenges.

Broad use of organo-molybdenum compounds has been limited primarily because of limited solubility in finished engine oils systems. This problem has manifested itself in two ways. First, it prevents the formation of a stable engine oil additive system. Second, over time, fallout of the additive from the finished lubricant is possible. This has particularly been a problem with molybdenum dithiocarbamates and is generally the result of poor solubility of the organic portion of the molecule. However, recent advances in ligand chemistry have resulted in the development of new molybdenum dithiocarbamate additives that show superior short and long term solubility properties [67]. More research need to be en done to better understand the mechanism by which friction modifiers function in engine oils [68-70].

\subsubsection{Anti-wear additives}

The most widely used anti-wear additive for lubricants is ZDDP (or ZnDTP). The chemical structure of ZDDP is shown in Fig. 21. The reason ZDDP is so widely used is due to its superior performance as an anti-wear additive in a wide variety of applications, especially engine oils. Its effectiveness is so superior to the next best alternatives that specifications require its use as a means of avoiding warranty issues in the field. Its effectiveness is due to the unique combination of zinc, sulfur and phosphorus chemistry that produces 


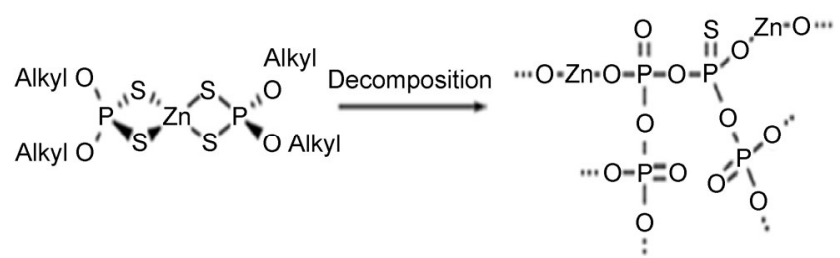

Fig. 21 Structure of ZDDP and mechanism of ZDDP function in engine oils.

superior tribo-films for protecting machinery of all types. Even over the years as engine technology has evolved, ZDDP appears to remain as the workhorse anti-wear additive for internal combustion engines.

A great deal of research has been done to better understand the mechanism of ZDDP function in engine oils [71-73]. In general ZDDP functions by decomposing on the metal surface to form complex zinc and iron based polyphosphate films. An idealized representation of the ZDDP mechanism and surface chemistry is shown in Fig. 22. Under lubricated sliding conditions of high load and temperature, the glassy zinc polyphosphate exhibits an increase in modulus, an effect that gives the film a "smart" wear resistant behavior by forming both zinc and iron polyphosphate as shown in Fig. 22. Thus when the load increases during engine startup the zinc and iron based polyphosphate tribo-film becomes stronger to enhance the anti-wear benefits when they're needed most. As shown in Fig. 22, the organic ZDDP compound can generate simultaneous formation of OMM and OIC reaction films at elevated temperature and loading. Anti-wear pads of iron phosphates and a durable anti-wear film containing higher concentrations of $S$, $\mathrm{Zn}$, and $\mathrm{P}$ form (called OIC-Zn film). OMM layers worn out and diminished during sliding process but OIC-Zn films form a strong protection layer from wear and scuffing. In addition, OIC-Zn films can induce a film formation of iron oxide, metallic iron, and iron carbide. These ZDDP induced films have much higher loading capacity and serve as an anti-wear and anti-scuffing film to protect steel substrates.

Although ZDDP is well recognized as the industry standard anti-wear additive, in recent years it has come under attack for two key reasons. First, the phosphorus in ZDDP has been proven to poison the automotive catalyst used for emissions control. As a result limits on the amount of ZDDP allowed in engine oils have been mandated. Second, the zinc metal in ZDDP contributes to the ash content of the lubricant which has a detrimental effect on diesel engine diagnostics systems. In addition, zinc is becoming a concern because it's a heavy metal which is undesirable for a number of reasons including environmental aspects. For these reasons ashless anti-wear additives are growing in interest.

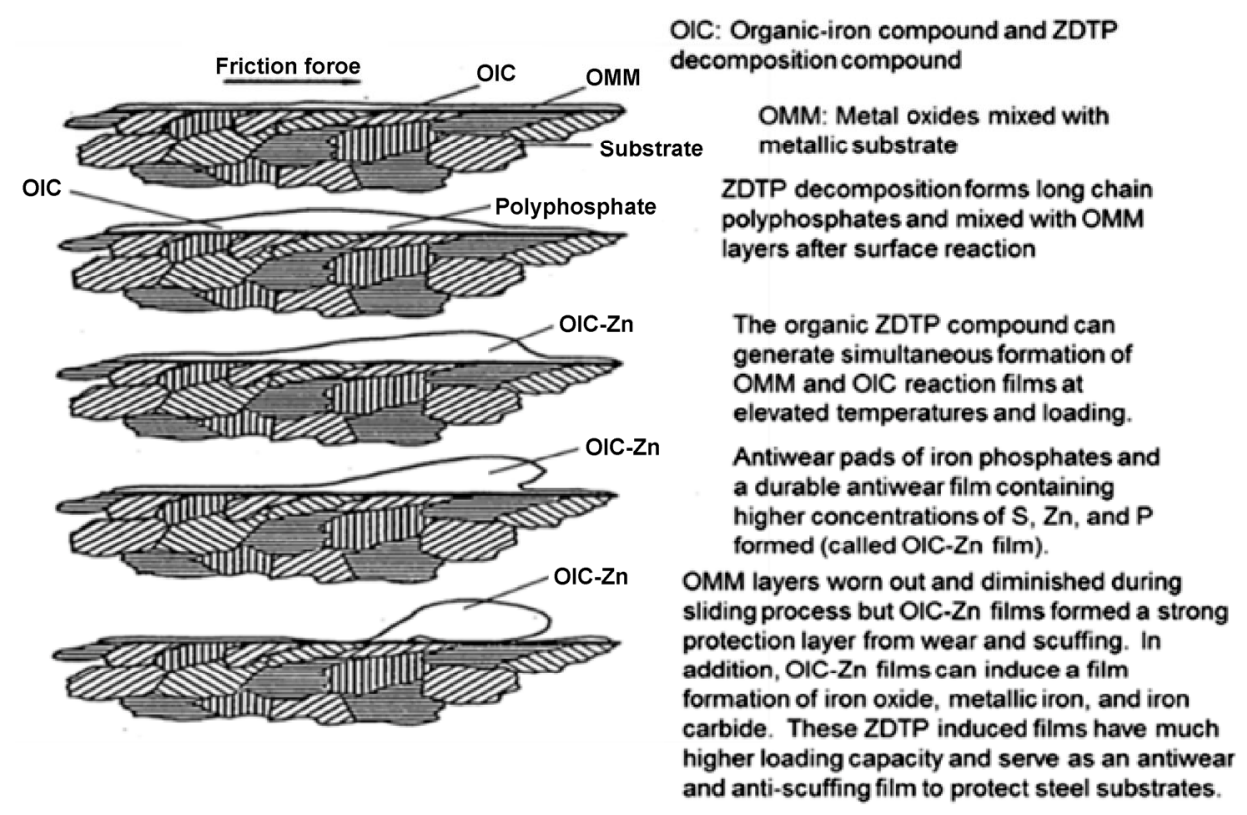

Fig. 22 Antiwear film formation mechanism by $\mathrm{ZnDTP}$. 
Ashless anti-wear additives can fall into two categories. The first grouping represents those that contain phosphorus. Examples of these are illustrated in Fig. 23. These function in a manner similar to ZDDP where the phosphorus reacts with the metal surface to produce tribo-films that are effective at suppressing wear. The most common chemistries in this grouping are aryl phosphates, aryl thiophosphates, amine phosphates and alkyl thiophosphates. These phosphorus-based anti-wear additives can be used as alternatives to ZDDP in formulations where lower ash contents are required. The second grouping represents those that are sulfur-containing and phosphorus-free. Examples of these are illustrated in Fig. 24. These function by modifying the tribo-films by incorporating additional sulfur in a way that enhances the elastic properties of the films. The most common chemistries

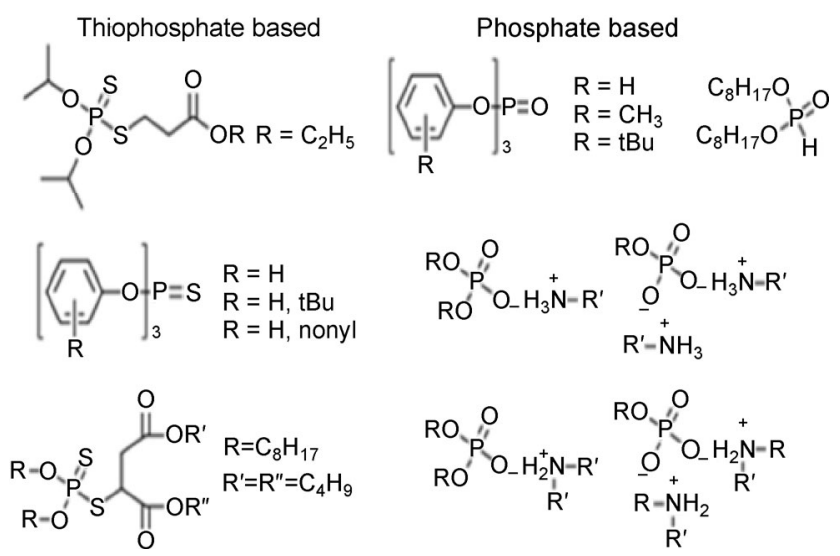

Fig. 23 Ashless anti-wear additives containing phosphorous.

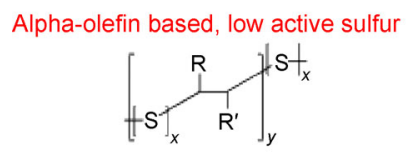

Ashless dithiocarbamate derivatives

Dimercapto-thiadiazole derivatives

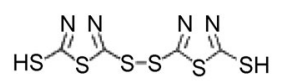

$\mathrm{R} / \mathrm{O}_{\mathrm{O}} \mathrm{O} \mathrm{OH}$
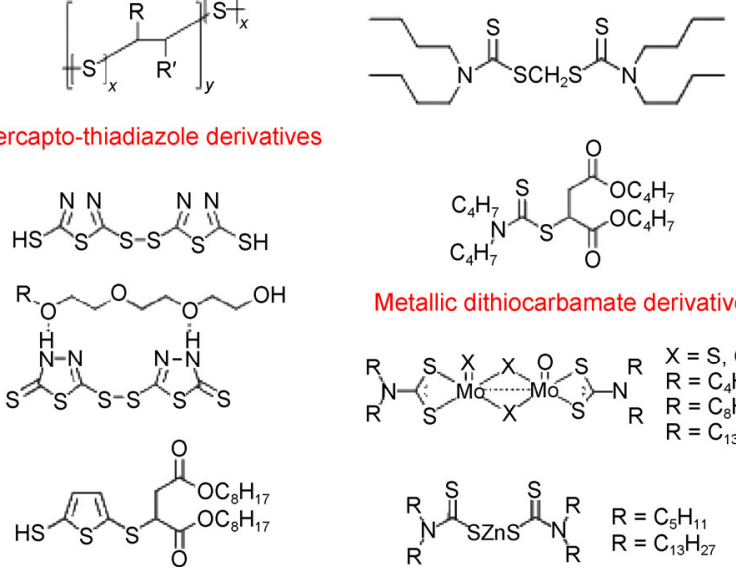

Metallic dithiocarbamate derivatives
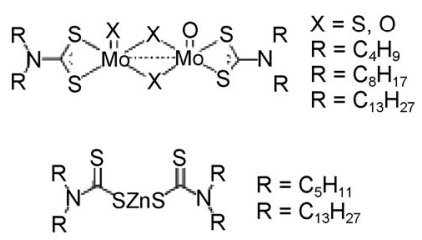

Fig. 24 Phosphorus free ashless and metallic anti-wear additives. in this group are the ashless dithiocarbamates, sulfurized olefins and fats, and oil soluble dimercaptothiadiazole derivatives. These sulfur chemistries can be used to supplement other anti-wear additives such as ZDDP or organo-molybdenum compounds.

\subsubsection{Balanced engine oil formulations}

A balanced engine oil formulation requires proper selection of both the base stock and the engine oil additives. The base oil and V.I. improver determine the viscometric properties of the finished oil. Detergents and dispersants are responsible for neutralizing acids and mitigating the harmful effects of deposits and sludge. The robustness or "durability" of the engine oil comes from its ability to protect the engine from wear while maintaining low friction for maximum fuel economy benefits. In modern engine oils very high demands are placed on the additives to minimize the harmful effects of sludge, varnish and deposits while maximizing the positive attributes associated with low friction/high fuel economy, robust wear protection and extended oxidation resistance. In modern lubricants a systematic approach must be taken in order to achieve this:

(a) Proper selection of base stocks and V.I. improvers to develop low viscosity lubricants that maximize hydrodynamic lubrication.

(b) Use of organic friction modifiers to improve fuel economy by reducing friction in boundary and mixed lubrication regimes.

(c) Use of metallic/molybdenum based friction modifiers for extended and aged oil fuel economy benefits.

(d) Minimizing volatile phosphorus from ZDDP in order to protect the automotive three-way catalyst system.

(e) Applying phosphorus-free supplemental antiwear additives, usually molybdenum and/or sulfur based, to compensate for lower levels of ZDDP in the oil.

Examples of this approach are starting to appear in public documents $[74,75]$. This approach can effecttively result in a robust engine oil system that can deliver high fuel economy while minimizing wear and protecting the vehicles emission or diagnostic systems. The real challenge with this approach is to do it in a way that does not place a logistical challenge 
or cost burden on the industry. Indeed much of the modern research on engine oil additives revolves around developing solutions that can be managed in terms of raw material supply and cost.

\section{Impact of modern powertrain technology to automotive lubricant and tribology requirements}

Emerging powertrain technologies including gasoline direct injection (GDI), turbocharged, and hybrid vehicles are critical to meet fuel economy and reduced emission targets which will generate unique opportunities for future propulsion systems. Improvement of fuel economy has been one of the most important challenges for the automotive industry. The turbocharged, direct-injection spark ignition engine with downsizing is one of the technical solutions that have been used in the market. In the case of diesel engines, the turbocharger has to be utilized to meet strict emissions regulations along with fuel economy improvement requirements. In both cases, engine oil technology plays a very important role in order to avoid potential problems in the market.

\subsection{Improving emergent powertrain systems}

The following technologies are being implemented to address the need for modern powertrains to meet global challenges for green energy, fuel efficiency and reduced emissions:

(1) Advanced gasoline and diesel engine demand for increasing power densities, improved specific fuel consumption (BSFC), reduced hydrocarbon emissions, improved combustion technology, higher injection pressure, and greater specific output and thermodynamic efficiencies for increased powertrain fuel economy and drivability.

(2) Environmental control measures of diesel engines include in-cylinder control of combustion processes, ignition timing, exhaust gas recirculation (EGR), and diesel particulate filters (DPF) have affected the ability of lubricants to control oil degradation and soot wear.

(3) Introduction of bio-based fuels and low sulfur, ash, and phosphorus (SAP) lubricants have moved to green convergence with environmentally friendly fuels and lubricants.
Responding to emerging engine technology, Global OEMs have the following feedbacks:

(1) Global OEM expectations for their next generation engine oil requirements will include the low speed pre-ignition (LSPI) frequency and turbocharger deposit control. In the case of diesel engines, the turbocharger has to be utilized to meet strict emissions regulations along with fuel economy improvement requirements. In addition, OEMs demand robust oil with respect to deposit control, oxidation, sludge and wear while maintaining good fuel economy performance.

(2) Global OEMs have initiated low viscosity lubricants to boost up fuel economy. For example, Japanese OEMs have developed low viscosity lubricants such as $0 \mathrm{~W}-20$ or even $0 \mathrm{~W}-16$ fuel-saving engine oil for advanced engines [48]. In addition, OEMs are deeply interested in the effects of surface coatings (coated on engine components) on friction and wear of low viscosity lubricants. They are also interested in the surface compatibility of coatings with engine lubricant additives and additive performance against DLC coatings.

(3) Most of the OEMs in Japan and Europe are still interested in the phosphorus limits or the ash content of engine oils. Recently Toyota has developed a new formulation technology which is expected to satisfy both LSPI prevention performance and these conventional performances [76]. Toyota R\&D Center has focused on two approaches: enhancement of LSPI prevention performance by adding a booster component and substitution of calcium for a less reactive component to balance performances including LSPI prevention [76]. They have verified effectiveness of the approaches by increasing dosage of molybdenum used as friction modifier and replacing calcium detergent system with magnesium counterpart. These technologies can be applicable for future ILSAC GF-6 engine oil, where LSPI prevention performance specification is expected to be implemented.

\section{Summary and conclusions}

Emerging powertrain technologies including gasoline direct injection (GDI), turbocharged, and hybrid vehicles are critical to meet fuel economy and reduced emission 
targets which will generate unique opportunities for future propulsion systems and lubrication requirements.

In summary, the major development trends will be focused on the following:

- Automotive tribology development is a critical enabler for improved engine fuel efficiency, powertrain durability, and vehicle performance.

- Automotive tribological research and applications will be driven by powertrain manufacturers and additive suppliers who want improved fuel economy, powertrain system efficiency, and improved product performance.

- Unconventional lubricant and additive approaches such as low phosphorous and high molybdenum (LPHM) and ashless antiwear additives technologies offer "step out" performance benefits for fuel economy, wear prevention, deposit control and three-way catalyst system protection versus conventional lubricant and additive approaches.

- In the case of diesel engines, the turbocharger has to be utilized to meet strict emissions regulations along with fuel economy improvement requirements. In addition, OEMs demand robust oil with respect to deposit control, oxidation, sludge and wear while maintaining good fuel economy performance.

Open Access: The articles published in this journal are distributed under the terms of the Creative Commons Attribution 4.0 International License (http://creativecommons.org/licenses/by/4.0/), which permits unrestricted use, distribution, and reproduction in any medium, provided you give appropriate credit to the original author(s) and the source, provide a link to the Creative Commons license, and indicate if changes were made.

\section{References}

[1] Holmberg K, Andersson P, Erdemir A. Global energy consumption due to friction in passenger cars. Tribol Int 47: 221-234 (2012)

[2] Holmberg K., Andersson P, Nylund O, Mäkelä K. Global energy consumption due to friction in trucks and buses. Tribol Int 78: 94-114 (2014)

[3] Allmaier H, Knauder C, Salhofer S, Reich F, Schalk E,
Ofner H, Wagner A. An Experimental study of the load and heat influence from combustion on engine friction. Int J Eng Res 17(3): 347-353 (2016)

[4] Sandoval D, Heywood J. An improved friction model for spark-ignition engines. SAE Paper \# 2003-01-0725, Society of Automotive Engineers, Warrendale, PA, 2003.

[5] Taraza D, Henein N A, Ceausu R, Bryzik W. Engine friction model for transient operation of turbocharged, common rail diesel engines. SAE Paper \# 2007-01-1460, SAE, Warrendale, PA, 2007.

[6] Patton K J, Nitschke R G, Heywood J B. Development and evaluation of a friction model for spark-ignition engines. SAE Paper \# 890836, Society of Automotive Engineers, Warrendale, PA, 1989.

[7] Richardson D. Review of power cylinder friction for diesel engines. J Eng Gas Turbine Power, Trans the ASME 122(4): 506-519 (2000)

[8] Quillen K, Stanglmaier R H, Moughon L, Takata R, Wong V, Reinbold E, Donohue R. Friction reduction by piston ring pack modifications of a lean-burn 4-stroke natural gas engine: Experimental results. In Proceedings of ASME ICED Spring Technical Conference, Aachen, Germany, 2006, ASME Paper ICES2006-1327.

[9] Quillen K, Stanglmaier R H, Wong V, Reinbold E, Donahue R, Tellier K, Carey V. Friction reduction due to lubrication oil changes in a lean-burn 4-stroke natural gas engine: Experimental results. In Joint Rail Conference \& Internal Combustion Engine Division Spring Technical Conference, Pueblo, Colorado, 2007, ASME Paper JRCICE 2007-40128.

[10] Nakada M. Piston and piston ring tribology and fuel economy. In Proceedings of the International Tribology Conference, Yokohama, 1995

[11] Taylor C M. Engine Tribology. Amsterdam: Elsevier Science Publishers, 1993

[12] Heywood, J. Internal Combustion Engine Fundamentals. McGraw-Hill, New York, NY, 1988.

[13] James C J. Analysis of parasitic losses in heavy duty diesel engines. M.S. Thesis. Department of Mechanical Engineering, Massachusetts Institute of Technology, Cambridge, MA, 2012.

[14] Mansouri S H, Wong V W. Effects of piston design parameters on piston secondary motion and skirt-liner friction. SAE Paper \# 2004-01-2911, Society of Automotive Engineers, Warrendale, PA, 2004.

[15] Moughon L. Effects of piston design and lubricant selection on reciprocating engine friction. M.S. Thesis. Department of Mechanical Engineering, Massachusetts Institute of Technology, Cambridge, MA, 2006. 
[16] Patir N, Cheng H S. Application of average flow model to lubrication between rough sliding surfaces. ASME J Lubr Tech 101: 220-230 (1979)

[17] Greenwood J A, Tripp J. The Contact of two nominally flat surfaces. Proc Inst Mech Engrs 185: 625-633 (1971)

[18] Smedley G. Piston ring design for reduced friction in modern internal combustion engines. M.S. Thesis. Department of Mechanical Engineering, Massachusetts Institute of Technology, Cambridge, MA, 2004.

[19] Allmaier H, Priestner C, Franz Markus R, Novotny-Farkus F. Predicting friction reliably and accurately in journal bearings - A systematic validation of simulation results with experimental measurements. Tribol Int 58: 20-28 (2013)

[20] Sander D E, Allmaier H, Priebsch H H, Reich F M, Witt M, Füllenbach T, Skiadas A, Brouwer L, Schwarze H. Impact of high pressure and shear thinning on journal bearing friction. Tribol Int 81: 29-37 (2015)

[21] Wachtmeister G, Hubert A. Rotation of a piston pin in the small connecting rod eye during engine operation. $M T Z$ Worldwide 69(12): 52-57 (2008)

[22] Nishikawa C. Optimization of semi-floating piston pin boss formed by using oil-film simulations. SAE Paper \# 2012-010908, Society of Automotive Engineers, Warrendale, PA, 2012.

[23] Wang X, Du J, Zhang J. (2011) 'Mixed lubrication analysis of piston pin bearing in diesel engine with high power density. In ASME/STLE 2011 International Joint Tribology Conference, Los Angeles, CA, 2011, ASME Paper \# IJTC 2011-61185.

[24] Ligier J, Ragot P. Piston pin: Wear and rotating motion. SAE Paper \# 2005-01-1651, Society of Automotive Engineers, Warrendale, PA, 2005.

[25] Takiguchi M, Suhara T, Tsuneo S. Reduction of friction for piston pin boss bearing of automotive gasoline engine by utilizing oil around the boss. American Society of Mechanical Engineers, New York, NY, 1998, ASME Paper \# 98-ICE-101.

[26] Bishop I N. Effect of design variables on friction and economy. SAE Trans 73: 334-358 (1965)

[27] Lee S, Shannon B A, Mikulec A, Vrsek G. Applications of friction algorithms for rapid engine concept assessments. SAE Paper \# 1999-01-0558, Society of Automotive Engineers, Warrendale, PA, 1999.

[28] Wang Y. Introduction to engine valvetrains. Special Publication, by Society of Automotive Engineers, Warrendale, PA, 2007.

[29] Staron J T, Willermet P A. An analysis of valve train friction in terms of lubrication principles. SAE Paper \# 830165, Soc. of Automotive Engineers, Warrendale, PA, 1983.
[30] Comfort A. An introduction to heavy-duty diesel engine frictional losses and lubricant properties affecting fuel economy-Part I. SAE Paper \# 2003-01-3225, Society of Automotive Engineers, Warrendale, PA, 2003.

[31] Beloiu D M. 'Modeling and analysis of valve train, Part IConventional systems. SAE Int J Eng 3(1): 850-877 (2010)

[32] Gangopadhyay A, Soltis E, Johnson M D. Valvetrain friction and wear: Influence of surface engineering and lubricants. Proc Inst Mech Eng Part J: J Eng Tribol 218: 147-156 (2004)

[33] de Paula Pignatti T, Miziara W, Esteves da Cunha R. Reduced friction for a four cylinder two valve otto engine valve train. SAE Paper \# 2011-36-0208E, Society of Automotive Engineers, Warrendale, PA, 2011.

[34] Takata R, Li Y, Wong V. Effect of liner surface texturing on ring/liner friction in large-bore engines. In Proceedings of ICEF06, ASME Internal Combustion Engine Div. 2006 Fall Technical Conf., Sacramento, Calif., USA, 2006, Paper ICEF2006-1525.

[35] Hamilton D B, Walowit J A, Allen C M. A theory of lubrication by microasperities. ASME J Basic Eng 88: 177-185 (1966)

[36] Anno J N, Walowit J A, Allen C M. Microasperity lubrication. ASME J Lubr Tech 90: 351-355 (1968)

[37] Anno J N, Walowit J A, Allen C M. Load support and leakage from microasperity-lubricated face seals. ASME $J$ Lubr Tech 91: 726-731 (1969)

[38] Kovalchenko A, Ajayi O, Erdemir A, Fenske G, Etsion I. The effect of laser surface texturing on transitions in lubrication regimes during unidirectional sliding contact. Tribol Int 38: 219-225 (2005)

[39] Sadeghi F, Wang C P. Advanced natural gas reciprocating engine: parasitic loss control through surface modification. ARES/ARICE Low Engine Friction Alliance Workshop, Cambridge, MA, 2005.

[40] Ronen A, Etsion I, Kligerman Y. Friction-reducing surfacetexturing in reciprocating automotive components. Tribol Trans 44: 359-366 (2001)

[41] Ryk G, Kligerman Y, Etsion I. Experimental investigation of laser surface texturing for reciprocating automotive components. Tribol Trans 45: 444-449 (2002)

[42] Siripuram R, Stephens L. Effect of deterministic asperity geometry on hydrodynamic lubrication. ASME J Tribol 126: 527-534 (2004)

[43] Hsu S. Integrated surface modification technology development. Presented at Oak Ridge National Laboratory on 9/15/2005, http://web.ornl.gov/sci/propulsionmaterials/pdfs/ 2005_Presentations/PM 9407\%20Presentation_Hsu.pdf. 
[44] Michail S K, Barber G C. The effects of roughness on piston ring lubrication Part I: Model development. Tribol Trans 38: 19-26 (1995)

[45] Jocsak J, Li Y, Tian T, Wong V W. Analyzing the effects of three-dimensional cylinder liner surface texture. In ICEF 2005, Ottawa, Canada, 2005, \#ICE 2005-1333.

[46] Moore J. Future automotive powertrain outlook. SAE Fuels and Lubricants Committee Report, 2013.

[47] Howard K. Turbocharged direct injection is engine oil's next big hurdle. LUBES'N'GREASES Magazine, 2013.

[48] Tung S C. "Impact of modern engine innovation to the future tribology requirements. Keynote presentation at German Tribology Conference, Organized by German Tribology Society, Gottingen, Germany, 2014.

[49] Haycock R F, Caines A J, Hiller J. Automotive Lubricants Reference Book, Third Edition. Society of Automotive Engineers, Warrendale, PA, 2008.

[50] Sappok A, Munnis S, Wong V W. Individual and synergistic effects of lubricant additive components on diesel particulate filter ash accumulation and performance. In ASME 2012 Internal Combustion Engine Division Spring Technical Conference, Turin, Italy, 2012, ASME Paper \# ICES 201281237.

[51] McGeehan J A, Moritz J, Shank G, Kennedy S, Stehouwer D, Urbank M, Belay M, Goodier S, Cassim A, Runkle B, et al. API CJ-4: Diesel oil category for both legacy engines and low emission engines using diesel particulate filter. SAE Paper \# 2006-01-3439, Society of Automotive Engineers, Warrendale, PA, 2006.

[52] Bodek K M, Wong V W. The effects of sulfated ash phosphorus and sulfur on diesel aftertreatment systems-A review. SAE Paper \# 2007-01-1922. JSAE \# 20077200, Society of Automotive Engineers, Warrendale, PA., 2007.

[53] Sappok A, Munnis S, Wong V. Individual and synergistic effects of lubricant additive components on diesel particulate filter ash accumulation and performance. In ASME 2012 Internal Combustion Engine Division Spring Technical Conference, Turin, Italy, 2012, ASME Paper\# ICES 201281237.

[54] Wasserscheid P, Keim A W. Introduction of ionic liquids. Chem Int Ed Engl 39: 3772 (2000)

[55] Syed Q A, Rizwi A. Comprehensive Review of Lubricant Chemistry, Technology Selection, and Design. ASTM Handbook, ASTM, 2009.

[56] Mathias W. Non-petroleum-based, no/low SAP and bionotox engine oil development and testing. Tung S, Totten G Ed. In ASTM Automotive Lubricant and Testing Handbook, 2013.
[57] Molewyk M A. In-situ control of lubricant properties for reduction of power cylinder friction through thermal barrier costing. M. S. Thesis. Department of Mechanical Engineering, Massachusetts Institute of Technology, Cambridge, MA, 2014.

[58] Haycock R F, Caines A J, Hiller J. Automotive Lubricants Reference Book, Second Edition. Society of Automotive Engineers, Warrendale, PA, 2004.

[59] Tung S, Totten G Ed. ASTM Automotive Lubricant and Testing Handbook Chapter 2 and Chapter 6. ASTM/SAE MNL, 2013.

[60] Mortier R M, Fox M F, Orszalik S T. Chemistry and Technology of Lubricants, Third Edition. Springer, Dordrecht, Netherlands, 2010.

[61] Schwartz S, Tung S, McMillan M. Automotive lubricants. Totten G Ed. In Fuels and Lubricants Handbook. ASTM, 2005.

[62] Muller M, Fan J, Spikes H. Design of functionalized pama viscosity modifiers to reduce friction and wear in lubricating oils. ASTM Int 4(10): JAI100956 (2007)

[63] Kenbeek D, Buenemann T, Rieffe H. Review of organic friction modifiers - Contribution to fuel efficiency? SAE Technical Paper 2000-01-1792, Society of Automotive Engineers, Warrendale, PA, 2000.

[64] Stipanovic A, Schoonmaker J. The impact of organomolybdenum compounds on the frictional characteristics of crankcase engine oils. SAE Technical Paper 932779, Society of Automotive Engineers, Warrendale, PA, 1993.

[65] Gatto V J, Bezjak Y L. The antioxidant properties of organomolybdenum compounds in engine oils. Tribol $\mathrm{Lubr}$ Tech 59(10): 40-47 (2003)

[66] Yao J, Aguilar G, Mazzamaro G. The friction-reducing, antiwear and antioxidation properties of an organomolybdenum lube additive without sulfur and phosphorus. Lubr Oil 22(3): 43-48 ( 2007)

[67] Donnelly S G, Aguilar G A, Chase K J, Wallack W T. Molybdenum dialkyldithiocarbamate compositions and lubricating compositions containing the same. U. S. Patent Application 20120/0264666, 2010.

[68] Ratoi M, Niste V B, Alghawel H, Suen Y F, Nelson K. The impact of organic friction modifiers on engine oil tribofilms. RSC Adv 9: 4278-4285 (2014)

[69] Tang Z, Li S. A review of recent developments of friction modifiers for liquid lubricants (2007-present). Current Opinion in Solid State and Materials Science 18(3): 119-139 (2014)

[70] Martin J-M, Grossiord C, Varlot K, Vacher B, Le Mogne T. Friction reduction mechanism of MoDTC. Nisseki Mitsubishi 
Rebyu 43(1): 5-11 (2001)

[71] Spike H A. The history and mechanisms of ZDDP. Tribol Lett 17: 465-485 (2005)

[72] Zhang Z, Yamaguchi E S, Kasrai M, Bancroft G M. Tribofilms generated from ZDDP and DDP on steel surfaces: Part1, growth, wear and morphology. Tribol Lett 19(3): 211-220 (2005)

[73] Zhang Z, Yamaguchi E S, Kasrai M, Bancroft G M, Liu X, Fleet M E. Tribofilms generated from ZDDP and DDP on steel surfaces: Part 2 Chemistry. Tribol Lett 19(3): 221-229 (2005)

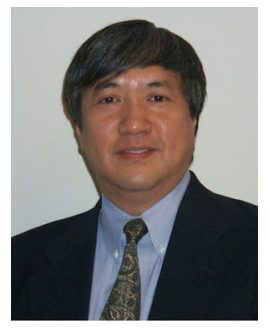

Victor WONG. He obtained his $\mathrm{PhD}$ and MS degrees in mechanical engineering from the Massachusetts Institute of Technology (MIT), USA, and a Master of Business Administration degree from IndianaUniversity-Purdue-University, USA, in 1982. Early in his career, he spent a brief period at Detroit Diesel Allison Division of General Motors Corporation, Detroit, Michigan, USA and eight years at Cummins Engine Company, Columbus, Indiana, USA where he headed the Combustion and Emissions Research and later Lubrication and Cooling systems Departments. He has been back to MIT since 1986, where he is currently Director of the MIT Low Ash Diesel Emissions Research Consortium and Principal Research Scientist in the Department of Mechanical Engineering.

During his long stretch at MIT, Dr. Wong led students and researchers in a wide range of internal combustion engine research areas: from fuels and combustion, low-friction component and lubricant research, to lubrication and diesel emissions. In 1989, he started with his colleagues an Industrial Research
[74] Esche C K, Mazzamaro G A, Bartels T, Gray D B. Fuel efficient lubricating oils. U.S. Patent Application 2015/ 0133352, 2015.

[75] Mazzamaro G A, Donnelly S G, Hiza R J. Ultra low phosphorus lubricant composition. U.S. Patent Application 2014/0228264, 2014.

[76] Onodera K, Kato T, Ogano S, Sekiyu K K, Fujimoto K, Kato K. Engine oil formulation technology to prevent preignition in turbocharged direct injection spark ignition engines. Presented at the SAE 2015 Fall Conference Powertrain, Fuels, and Lubricants, Kyoto, Japan, 2013.

Consortium on Lubrication in I.C. Engines, which is still continuing today. In 2005, he co-founded another research consortium at MIT on Low-Ash Lubricants and Diesel Emissions with major engine, lubricant and additives OEMs participating to investigate the interactions of lubricant/additives on engine durability and diesel engine emission aftertreatment systems. This program is still continuing today.

Dr. Victor Wong is a Fellow of the Society of Automotive Engineers (SAE), a Fellow of the American Society of Mechanical Engineers (ASME), and a Fellow of the Society of Tribologists and Lubrication Engineers (STLE). From SAE, he won the SAE Lubricants Award twice, once in 1992 and again in 2002. He also received the SAE Arch T. Colwell Merit Award twice in 1994 and 2014, an SAE Award for Outstanding Research in Diesel Engines. From ASME, he received several awards for best paper, engineering management, and for achievement in engine friction and efficiency. Victor Wong served within the last fifteen years as the Chair of the IC Engine Division at ASME, Chair of the Engine and Drivetrain Committee of STLE, and currently as an Associate Editor of Tribology Transactions since 2010. 


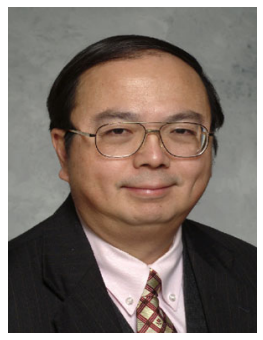

Simon TUNG. He holds a Ph.D. degree in chemical engineering from Rensselaer Polytechnic Institute and an MBA Degree from University of Michigan-Ann Arbor. Dr. Tung has been involved in the automotive industry since joining General Motors Research Laboratories in 1982. While there, Dr. Tung led pioneering research and development on automotive powertrain tribology and lubrication engineering, and Dr. Tung was appointed as Technical Fellow to lead the advanced energy efficient lubricant technology and discovery research programs in the General Motors R\&D Center in 2003. In 2008, Dr. Tung joined the Industrial Technology Research Institute as General Director, where Dr. Tung was responsible to manage all $R \& D$ programs in the Energy and Environmental Research Laboratories. Dr. Tung made significant contribution in the research areas of green energy, energy storage system, hydrogen energy, and greenhouse emission reduction.

Dr. Tung has been appointed by R.T. Vanderbilt to serve as Global OEM Manager in 2011. In his new position, Dr. Tung led Global OEM Technology and Liaison activities working on developing and disseminating the global OEM advanced lubricant requirements and energy resources technologies.

Dr. Tung has 186 publications that appear in 7 different professional journals; cover such diverse subjects as automotive engineering, advanced materials, surface engineering, powertrain tribology, and manufacturing. He also holds 25 U.S. and International Patents on novel tribological materials and innovation methods for reducing friction and wear in powertrain components and manufacturing process. Dr. Tung has received many distinguished honors, including being named an SAE Fellow and a Fellow in the Society of Tribologists and Lubrication Engineers as well as receiving the Gold Award from the Engineering Society of Detroit. Recently he was honored with SAE International's Edward N. Cole Award for Automotive Engineering Innovation during the SAE 2011 World Congress. In addition, Dr. Tung has been recognized by SAE for the winner of the SAE Franz Pischinger Powertrain Innovation Award in April, 2013, based on his outstanding professional achievements, leadership, innovative research, and their impact in the fields of automotive engineering, and powertrain systems. Recently Dr. Tung has won the SAE 2015 International Leadership Citation Award to recognize his distinguished leadership and outstanding international contributions. 